IIIIIIII BANK OF CANADA

BANQUE DU CANADA

Staff Working Paper/Document de travail du personnel 2020-35

Last updated: August 31, 2020

\title{
Why Do Central Banks Make Public \\ Announcements of Open Market Operations?
}

by Narayan Bulusu

Funds Management and Banking Department Bank of Canada, Ottawa, Ontario, Canada K1A 0G9 nbulusu@bankofcanada.ca

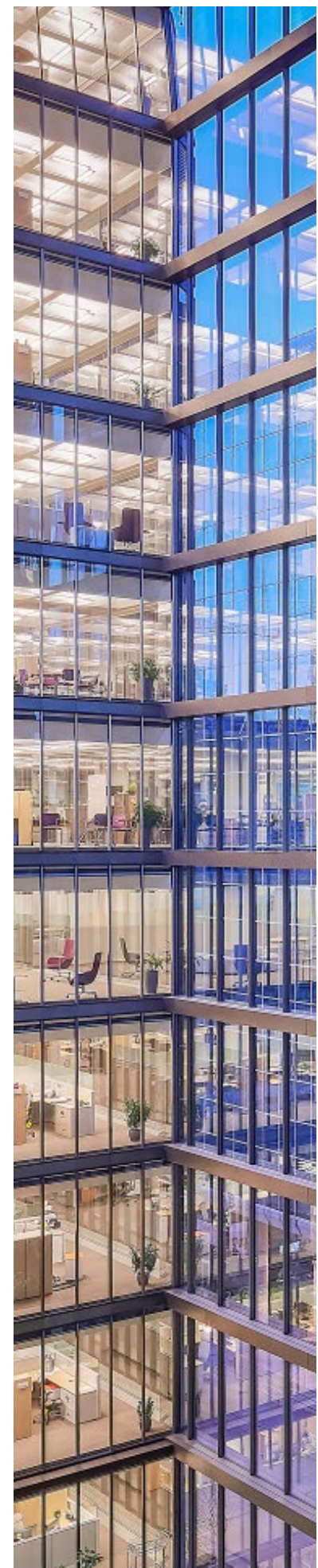

Bank of Canada staff working papers provide a forum for staff to publish work-in-progress research independently from the Bank's Governing Council. This research may support or challenge prevailing policy orthodoxy. Therefore, the views expressed in this paper are solely those of the authors and may differ from official Bank of Canada views. No responsibility for them should be attributed to the Bank. 


\section{Acknowledgements}

I am thankful to Patrick Augustin, Max Bruche, Stefania D'Amico, Antonio Diez de los Rios, Itay Goldstein, Reint Gropp, Stephen Hansen, Charles Kahn, Cyril Monnet, Sebastian Mueller, Stefan Nagel, Paolo Pasquariello, Francisco Rivadeneyra, Rodrigo Sekkel, Gregor von Schweinitz, Christoph Weber and participants at the 23rd German Finance Association Meetings, 25th MBF Rome Conference, 20th IWH-CIREQ-GW Macroeconometric Workshop and seminars at IESE Business School and colleagues at the Bank of Canada for comments on previous versions of the paper. I also thank Jacob Thompson for research assistance and Danny Auger and Joanna Roberts for helpful discussions about the implementation of Bank of Canada operations. 


\section{Abstract}

Central banks make public the results of open market operations (OMOs), which they use to adjust the liquidity available to the financial system to maintain the short-term borrowing rate in the range compatible with achieving their monetary policy objectives. This paper shows that such announcements are costly because they moderate the impact of changes in supply achieved through OMOs. Nevertheless, communication of OMOs is desirable because it improves the transparency of the funding market, which makes the price of liquidity-a key input into economic decision making-more reflective of underlying demand and supply of liquidity.

Bank topics: Central bank research, Monetary policy implementation

JEL codes: D52, E58, G21 


\section{Introduction}

Central banks use open market operations (OMOs) to fine-tune the quantity of funds available to the financial system. They do this to maintain short-term interest rates at a level compatible with their policy objectives (such as the inflation target). For example, in response to a lending rate that is higher than desired, central banks hold an auction at which eligible financial institutions can bid to sell government securities to, or to obtain short-term loans of cash from, the central bank. The resulting injection of cash into the economy is designed to lower the price of liquidity and reduce its gap to the target rate.$^{1}$

Several studies confirm the standard view of the monetary transmission mechanismthat central banks influence short-term borrowing costs by adjusting the aggregate funds available in the economy (Hamilton, 1997; Carpenter and Demiralp, 2006; Kopchak, 2011). However, the rationale behind why central banks choose to make public announcements of OMOs has not been explored. This paper shows that OMO announcements help implement monetary policy by revealing information about aggregate financial conditions, thus aiding price discovery in the market for short-term loans.

OMO announcements are a valuable source of information because they are public signals of aggregate conditions in the market for liquidity, in which trades are largely negotiated over the counter (Krishnamurthy, Nagel, and Orlov, 2014; Afonso and Lagos, 2015). Overthe-counter (OTC) markets are characterised by limited pre- and post-trade transparency, with the terms of individual transactions known only to the two parties involved in the negotiation. Note that the value of the announcement does not depend on the central bank possessing superior information. Rather, the central bank plays the role of an auctioneer who receives private bids for short-term loans and communicates the results, which market participants use to update their expectation of aggregate demand and supply in the funding market.

${ }_{1}^{1}$ Schreft and Smith (1998) and Rocheteau, Wright, and Xiao (2018) discuss the macroeconomic consequences of the change in the relative mix of government bonds and currency achieved following central bank OMOs. 
Using data on overnight loans in Canada, we quantify the supply and information effects of OMOs conducted by the Bank of Canada (BoC). The overnight interest rate for borrowing funds against Government of Canada (GoC) securities deposited as collateral to the cash lender falls by 0.5 basis points (bps) for every Can $\$ 1$ billion the BoC injects. 2 The information in an OMO announcement depends on the discrepancy between the expectation and the realisation of the event, i.e., how surprised market participants are by the BoC operation. For example, the borrowing rate rose by 0.2 bps despite the BoC injecting Can $\$ 990$ million on December 20, 2011. We estimate that the market placed only a $2.7 \%$ probability of an $\mathrm{OMO}$ on that day; therefore, the announcement of this unexpected intervention led the market to revise upwards its belief about the demand for liquidity. Cash lenders reacted by raising the interest rate by 0.8 bps in the 24 hours following the OMO, counteracting the 0.5 bps decrease achieved by the BoC supply of liquidity. In contrast, the information revealed by the Can $\$ 1.5$ billion operation on December 29, 2015, was negligible (0.005 bps to be precise) because the market expected the BoC to intervene with $99.5 \%$ probability. Thus, the 0.6 bps fall in the overnight interest rate in the 24 hours after the event was almost entirely driven by the increase in supply: $!^{3}$

We see therefore that the announcement of the operation is costly for the BoC because it could moderate the decrease in overnight lending rates achieved per Canadian dollar of liquidity injected $4^{4}$ Nevertheless, OMO communication improves the quality of the funding liquidity market by making prices more reflective of the underlying aggregate demand and supply of cash. Thus, in line with major central banks, the BoC in effect trades off the diminished impact of its supply against the benefits of improving the information content of funding costs in the economy. This paper highlights that the details of implementing

\footnotetext{
${ }^{2}$ The size of the liquidity effect in the United States has been estimated at between 1 bp and 3 bps per \$US1 billion liquidity injected through OMOs by the Federal Reserve Bank of New York (Hamilton, 1997. Carpenter and Demiralp 2006).

${ }^{3}$ As we show in Section 5.2 , the market also learns from the announcement of the quantity of overnight loans allotted in the OMO.

${ }^{4}$ OMOs are also used to drain liquidity from the system when the prevailing borrowing rate is below the target rate. However, since liquidity withdrawals through OMOs occurred in fewer than $1 \%$ of the days in our sample, we exclude them from our analysis.
} 
seemingly routine and mechanical central bank operations play an important role in the effectiveness of monetary policy implementation.5

Access to time-stamped transaction-level data on overnight loans is central to our ability to disentangle the supply and information effects of OMOs. Firstly, since liquidity injections are undertaken neither at the start nor at the end of the day, the granularity of our dataset allows us to accurately measure the change in the borrowing cost after the operation. The need for high-frequency data on outcomes to measure the impact of news generated by central banks has been recognised at least since Kuttner (2001). Secondly, the ability to separate the state of the funding market before and after the operation helps us address concerns of reverse causality (see Rigobon and Sack (2004) for an alternative estimation procedure). Central banks are able to use information only up to the scheduled time of the OMO to decide whether to conduct one. Because the trigger for liquidity injection is well known, market participants can partially anticipate these operations, which influences their trades in the funding market before the auction. ${ }^{6}$ This implies that the operation affects the price of liquidity only to the extent that it is surprising. Our estimation therefore proceeds in two steps. Firstly, we use data up to the OMO to obtain the market's estimated probability of intervention. We measure the information generated by the operation (or lack thereof) as the error in this expectation, conditional on the outcome of the central bank's decision about the operation. Secondly, we regress the change in funding costs over the volume of liquidity injected by the BoC along with our measure of the communication value of the OMO to estimate their effects separately. This two-step procedure is recommended by Prabhala (1997) to correct the bias of traditional methods when events are not exogenous - especially when data on both events and non-events are available to the econometrician.

We verify the value of the conditional event study method in our setting, as well as the generality of our conclusions, by analysing the market for borrowing government bonds where

\footnotetext{
${ }^{5}$ Previous empirical studies on this topic focus on the impact of OMOs conducted by the Federal Reserve Bank of New York on the volatility of interest rates and the liquidity of US Treasuries (Harvey and Huang, 2002, Bartolini, Bertola, and Prati, 2002, Demiralp and Farley, 2005; Pasquariello, Roush, and Vega, 2020). ${ }^{6}$ The limited transparency of the OTC overnight loan market impedes perfect foresight.
} 
trades are also negotiated bilaterally and central banks are the lenders of last resort. Central banks use securities lending operations (SLOs) to lend those government securities with borrowing fees that are judged to be high enough to potentially disrupt financial intermediation 7 Using the two-step procedure outlined earlier - modified to incorporate bond-specific expectations of intervention - we find that the borrowing cost of a security falls by 20 bps per Can $\$ 1$ billion the BoC loans out. Securities with low ex ante probability of being involved in an SLO experience a countervailing increase in fees due to lenders adjusting their beliefs about its net borrowing demand upwards. For example, on June 7, 2010, despite the BoC lending Can $\$ 285$ million of the GoC bond with five years to maturity at issue with $4 \%$ coupon and maturing on September 1, 2010, its borrowing cost rose by 15.6 bps in the 24 hours following the operation. This was because the market anticipated an SLO in the bond with only $0.5 \%$ probability. Thus, the 5.7 bps fall in borrowing cost due to the increased supply was dwarfed by the 18.3 bps rise in fees due to the information revealed by the SLO. As an example of learning from non-events, note that the borrowing cost fell by 8.1 bps on October 4, 2015, for the GoC bond with 10 years to maturity at issue paying $3.25 \%$ coupon and maturing on June 1, 2021, despite no BoC operation in the bond. Since the estimated probability of BoC lending of the bond was $87.8 \%$, its absence communicated lower-than-expected demand for borrowing, which led to the fee dropping by 10.4 bps in the 24 hours following the scheduled SLO announcement.

Our analysis demonstrates how public announcements of their operations aid central banks in improving the quality of the price signals in the markets for borrowing cash and government securities. However, such communication is neither sufficient nor necessary for achieving their (monetary policy and financial stability) objectives. An announcement that reveals the aggregate conditions in the market for borrowing cash or government securities without an accompanying injection of supply could exacerbate the difference between the

$7^{7}$ Fontaine, Garriott, and Gray (2016) highlight the critical role played by the government securities lending market in maintaining market liquidity. Aggarwal, Bai, and Laeven (2020) discuss the financialstability implications of this market, which is also used for upgrading collateral quality. Baklanova et al. (2019) provide estimates of its size, emphasizing their importance for the US financial sector. 
desired and the prevailing lending cost and consequently be counterproductive to the goal of reinforcing the borrowing rate. Further, because all interventions involve a trade between the central bank and a subset of financial institutions, the information contained in the unannounced operation eventually percolates to the entire market after successive rounds of trading (Popper and Montgomery, 2001; Duffie, Giroux, and Manso, 2010). In such an environment, the central bank's public signals are valuable because they speed up the convergence of participants' information sets about the underlying conditions in the market for funding liquidity (Duffie, Malamud, and Manso, 2009; Iwatsubo and Kawanishi, 2014).

This paper highlights an aspect of central bank communication that has been peripheral to the large - and burgeoning - literature on the subject, which investigates how central bank 'words,' such as speeches, monetary policy reports, forecasts and even forward guidance (as opposed to the actions taken for conducting market operations that are the focus of this paper), affect the financial sector and the economy more broadly $]^{8}$ Since central bank words contain signals about both the stance of monetary policy and the state of the economy, researchers have developed methods to disentangle the two components to identify the source of their impact Cieslak and Schrimpf, 2019; Hansen, McMahon, and Tong, 2019, Jarociński and Karadi, 2020). In contrast, because market operations are conducted to support current policy and have no information content on future policy stance, central bank announcements of operations provide a clean setting for understanding the impact of communications about the state of the financial markets.

We proceed by providing a brief description of OMOs in Section 2, emphasising the details of BoC liquidity injections relevant to the choice of our empirical methods. Readers familiar with this institutional context may choose to proceed to the description of our empirical methodology in Section 3 .

\footnotetext{
${ }^{8} \mathrm{~A}$ meaningful summary of the literature is beyond the scope of this paper. An extremely limited set of salient papers in this area includes Kuttner (2001), Gürkaynak, Sack, and Swanson (2005), Hansen and McMahon (2016), Hubert (2015), D'Amico and Farka (2011), Berger, Ehrmann, and Fratzscher (2011) and Ehrmann and Talmi (2020). Blinder et al. (2008) contains a somewhat dated survey of the literature.
} 


\section{Central bank OMOs: relevant institutional details}

To fulfill their role as lenders of last resort, central banks make multiple facilities available to extend liquidity to the financial system. Some, such as the discount window, allow individual eligible institutions to directly request liquidity support from the central bank. Others, such as OMOs, are initiated by the central bank to fine-tune the market-wide supply of funds to support their monetary policy objectives. Specifically, central banks inject funds into (withdraw funds from) the financial system when the prevailing short-term borrowing rate is too high (low) compared with the target rate.

The most common market-wide adjustment of liquidity supply is achieved by the purchase or sale of government securities, or the lending or borrowing of cash against suitable collateral, implemented through auctions open to all eligible market participants.9 Central banks use a combination of their forecasts and information gleaned from market participants to estimate the funding needs of the financial sector that would be compatible with achieving the targeted interest rate. Because liquidity injection and withdrawal operations are based on these estimates, at least some aspects of such events are partially anticipated. For example, the European Central Bank (ECB) and the Bank of England conduct some OMOs - called, respectively, the main refinancing operation and indexed long-term repos - at pre-announced regular intervals to meet the anticipated demand for liquidity. Therefore, the timing of such operations is fully expected; however, their outcomes are uncertain. In contrast, the Federal Reserve Bank of New York and the Bank of Canada's OMOs are undertaken only when the supply of liquidity is judged to need adjustment to reinforce the target rate. This also introduces uncertainty about whether an operation would be conducted on any given day. Soon after the OMO concludes, central banks make an announcement - either to the general public or to auction participants - about the results of the operation, i.e., the volume and

\footnotetext{
${ }^{9}$ Details of OMOs conducted by central banks are typically made available on their external web pages. See, in particular, the relevant web pages of the Federal Reserve Bank of New York, Deutsche Bundesbank, Bank of England, Bank of Japan and Bank of Canada, accessible by clicking on the name of the relevant central bank in the footnote.
} 
price of lending in the $\mathrm{OMO} 10$

Because OMOs are undertaken during a trading date - rather than at the beginning or end of the day - access to granular, time-stamped data on overnight loan trades is necessary to accurately calculate the difference between the price of liquidity before and after intervention. Since our overnight loan data are from Canada, we provide some institutional details relevant to the empirical methodology described in Section 3 .

The BoC does not intend OMOs to replace overnight loan transactions between private financial institutions. Its intervention is designed only to ensure that the system-wide liquidity is compatible with its overnight rate target. Therefore, the BoC informs institutions eligible to participate in OMOs at 11:45 a.m. if it is accepting bids for overnight loans secured by eligible collateral, when most funding transactions are usually concluded ${ }^{11}$ Additionally, the reserve price at OMOs is set at a rate that disincentivises market participants from prioritising trading with the central bank instead of concluding transactions between themselves. For example, during our sample period, the BoC offered loans at the overnight target rate. The borrower would prefer to transact, if at all possible, with a participant willing to offer a marginally lower rate. Offering this rate would be beneficial to a lender with sufficient spare liquidity because any excess liquidity held at the BoC only earns 25 bps below the target rate 12

The BoC actively monitors the conditions in the market for overnight loans collateralised by GoC securities every day to prepare for its decision about whether to undertake an OMO. The information gathered includes the results of any auctions of cash by the GoC and confidential bilateral discussions between the BoC and key participants in the Canadian

\footnotetext{
${ }^{10}$ The delay between the conclusion of the OMO and its announcement ranges from a few seconds in the United States and Canada to up to about 15 minutes in Japan.

${ }^{11}$ In our sample from August 28, 2009, to December 31, 2015, an average of $70 \%$ (74\%) of all collateralised overnight loans by volume (number) are traded by 11:45 a.m. Note that during this period, OMOs were used to withdraw liquidity on only 12 days ( $0.81 \%$ of the sample). Due to this small sample size, we drop days of liquidity withdrawal from our analysis. Further details about so-called primary dealers, who are eligible to participate in OMOs, are available on the BoC's website.

${ }^{12}$ For a description of the corridor system operated by the BoC during our sample period, please see the relevant section on the BoC's website.
} 
financial system 13 Based on a synthesis of the acquired information, the BoC holds an auction if it judges one to be necessary to adjust the supply of liquidity to meet its rate target. Thus, the BoC auction merely serves to aggregate the information dispersed among market participants, whose ability to estimate the prevailing market-wide conditions is hampered by the lack of transparency about trading in the overnight loan market. Also note that, because OMOs are merely used to support the target rate, the BoC only reacts to marketwide funding needs and not to convey information about future monetary policy.

When the BoC communicates its decision to undertake an OMO at 11:45 a.m., the institutions eligible to participate in the auction receive a signal of the aggregate state of the overnight funding market. Note that the absence of a notification of the OMO may also provide a signal about the prevailing demand and supply conditions. Immediately after the conclusion of the auction at noon, the BoC makes a public announcement about the aggregate volume and price of the operation. During our sample period, the BoC offered up to Can $\$ 1.5$ billion in each $\mathrm{OMO}$ at the overnight rate. Thus, while the price does not contain additional information that is not included in the announcement of the operation, the market may learn about the prevailing liquidity conditions from the volume of loans taken up at the auction. As shown in detail in Section 3, we incorporate these institutional features into the design of our empirical analysis.

\section{Empirical methods}

Central bank communication about OMOs contains information to the extent that it surprises the market. Indeed, both OMO announcements and their absence can be surprising - the former when the market does not anticipate a liquidity injection, and the latter when it expects one with a high probability. Acharya (1988) develops conditional event study methods to use the information revealed by events as well as non-events for robust

\footnotetext{
${ }^{13}$ See https : //www. bankof canada.ca/wp-content/uploads/2014/03/terms_conditions_280116.pdf for details about Receiver General auctions, which the federal government uses to manage its cash flows.
} 
inference. Motivated by Heckman (1979), Prabhala (1997) recommends the use of a two-step procedure to account for the endogeneity of events - in this case, the central bank's decision about whether to inject liquidity 14

Because we do not observe the information possessed by individual financial institutions at 11:45 a.m., when the BoC informs eligible institutions about the decision to conduct the auction, we estimate a market-wide expectation of an OMO on each day. The market's ability to forecast liquidity injections is aided by the BoC's clear communication of the intervention criterion: when the prevailing lending rate is judged to be sufficiently above target. Therefore, our first step can be viewed as modelling the market's estimation of the overnight rate breaching this target at 11:45 a.m. The information revealed by the announcement of the operation is summarised by the expected value of the forecast error - concretely, a scaled version of the inverse Mill's ratio - obtained using the parameters estimated in the first stage. The effect of the announcement is obtained in the second stage by including the estimated information revealed as an additional regressor in a traditional event study setting.

\subsection{Estimating the OMO announcement effect}

At a publicly announced time $h_{o, t}$ on each day $t$, the BoC decides whether to conduct an OMO. The market uses the realisation of the vector $X_{h_{o, t}^{-}}$, observed just before $h_{o, t}$, to form its expectations of the probability of BoC intervention in the funding liquidity market. $X_{h_{o, t}^{-}}$ should be interpreted as the set of variables relevant to OMOs that is commonly observed by all market participants - including the BoC (see Section 4 for a more detailed discussion of these variables).

Assume that the market forms an expectation about a latent variable $\tau_{t}$ of the form $E\left(\tau_{t}\right)=\theta^{\prime} X_{h_{o, t}^{-}}$and knows that the BoC conducts an OMO if the realisation of $\tau_{t}$ is nonnegative. $\tau_{t}$ can be interpreted as the difference between the overnight lending rate at $h_{o, t}$ and the publicly known threshold that triggers the OMO. The market is aware that its

\footnotetext{
${ }^{14}$ See Amihud and Li (2006), Benston et al. (2003) and Nayak and Prabhala (2001) for other empirical applications of these methods.
} 
expectation $E\left(\tau_{t}\right)$ may have an error, given by $\psi_{t}=\tau_{t}-E\left(\tau_{t}\right)$, which is assumed to be normally distributed with mean zero and variance $\sigma^{2}$ and is independent over time. Thus, the $\mathrm{BoC}$ conducts an $\mathrm{OMO}$ - or OMOInd takes the value 1 -if $\tau_{t} \geq 0 \Rightarrow E\left(\tau_{t}\right)+\psi_{t}=$ $\theta^{\prime} X_{h_{o, t}^{-}}+\psi_{t} \geq 0$, and OMOInd $t_{t}=0$ if $\tau_{t}<0.15$

Soon after $h_{o, t}$, the market observes OMOInd and is then able to estimate the expected value of its error $E\left(\psi_{t}\right)$. If $O M O I n d_{t}=0, E\left(\psi_{t} \mid O M O I n d_{t}=0\right)=E\left(\psi_{t} \mid \psi_{t}+\theta^{\prime} X_{h_{o, t}^{-}}<\right.$ $0)=E\left(\psi_{t} \mid \psi_{t}<-\theta^{\prime} X_{h_{o, t}^{-}}\right)$. In contrast, if $O M O I n d_{t}=1$, then $E\left(\psi_{t} \mid\right.$ OMOInd $\left.d_{t}=1\right)=$ $E\left(\psi_{t} \mid \psi_{t}+\theta^{\prime} X_{h_{o, t}^{-}} \geq 0\right)=E\left(\psi_{t} \mid \psi_{t} \geq-\theta^{\prime} X_{h_{o, t}^{-}}\right)$. Our measure of the communication value of OMOs is this conditional expectation of $\psi_{t}$. Intuitively, if $\theta^{\prime} X_{h_{o, t}^{-}}$is below zero-implying that the expected overnight loan rate is below the intervention threshold-but the BoC conducted an OMO, the market would learn that $\psi_{t} \geq-\theta^{\prime} X_{h_{o, t}^{-}} \geq 0$, or that the net demand for funding liquidity was larger than expected, in the amount of $E\left(\psi_{t} \mid O M O I n d_{t}=1\right)$. Conversely, when the market has a high expectation for an OMO (because $\theta^{\prime} X_{h_{o, t}^{-}} \geq 0$ ) but the BoC does not conduct one, the market learns that $\psi_{t}$ is negative - reflecting lower-thanexpected net demand for funding liquidity - and also learns that the error in the expectation of net demand was greater in magnitude than $\theta^{\prime} X_{h_{o, t}^{-}}$.

Notice that when $\theta^{\prime} X_{h_{o, t}^{-}}$is much greater than zero, $\left|E\left(\psi_{t} \mid O M O I n d_{t}=0\right)\right|>\mid E\left(\psi_{t} \mid O M O I n d_{t}=\right.$ 1)|, i.e., a non-event reveals more information about the net demand for funding liquidity than an intervention when the market expects that there is a high probability of an OMO. Similarly, when $\theta^{\prime} X_{h_{o, t}^{-}}$is much less than zero, $\left|E\left(\psi_{t} \mid O M O \operatorname{Ind}_{t}=1\right)\right|>\mid E\left(\psi_{t} \mid O M O \operatorname{Ind}_{t}=\right.$ $0) \mid$. This is the sense in which the first-stage model captures the intuition that the information revealed by an OMO is linked to the surprise of the event.

Given the assumption that $\psi_{t} \stackrel{i . i . d}{\sim} N\left(0, \sigma^{2}\right)$, the expected information content of an OMO

\footnotetext{
${ }^{15}$ This discussion ignores that OMOs are also used to withdraw liquidity from the system. The framework described here can be generalised to include liquidity-injection and liquidity-withdrawal OMOs. However, the number of BoC OMOs to drain liquidity is too small in our sample (12 of 1,478 days) to obtain good estimates of the parameters of, e.g., an ordered probit model in the first stage.
} 
is given by

$$
\text { OMO_Comm }{ }_{t}=\left\{\begin{array}{l}
E\left(\psi_{t} \mid \text { OMOInd } d_{t}=0\right)=\sigma \frac{-\phi\left(\theta^{\prime} X_{h_{o, t}^{-}} / \sigma\right)}{1-\Phi\left(\theta^{\prime} X_{h_{o, t}^{-}} / \sigma\right)} \\
E\left(\psi_{t} \mid \text { OMOInd } d_{t}=1\right)=\sigma \frac{\phi\left(\theta^{\prime} X_{h_{o, t}^{-}} / \sigma\right)}{\Phi\left(\theta^{\prime} X_{h_{o, t}^{-}} / \sigma\right)},
\end{array}\right.
$$

where $\phi$ and $\Phi$ are the probability density function and the cumulative density function, respectively, of a standard normal distribution. The information content in OMOs is calculated by replacing $\theta$ by $\hat{\theta}$, which in turn is obtained by estimating the probit model $O M O I n d_{t}=1$ if $\theta^{\prime} X_{h_{o, t}^{-}}+\psi_{t} \geq 0$ and OMOInd $d_{t}=0$ if $\theta^{\prime} X_{h_{o, t}^{-}}+\psi_{t}<0$.

Under the assumption that the information revealed $\psi_{t}$ is normally distributed and independent over time, Prabhala (1997) shows that outcomes are linearly related to the expected surprise due to the communication of the event. Accordingly, we run the second-stage regression

$$
\Delta y_{t+1}=\alpha+\pi O M O_{-} C_{o m m}+\beta^{\prime} Z_{t+1}+\epsilon_{t},
$$

where $\Delta y_{t+1}$ is the change in the dependent variable of interest and $Z_{t+1}$ is the vector of control variables. We test the hypothesis that $\pi \neq 0$ to confirm that BoC communication of OMOs has a significant effect 16

The availability of time-stamped transaction-level data is crucial to our identification strategy. Central bank OMOs both influence and react to funding liquidity costs. Access to high-frequency data allows us to separate the funding trades that occurred before and after the operation. Only the former is a factor in the central bank's decision to inject liquidity, while the latter is affected by it. This ability to separate the variables that influence the central bank from the reaction to the central bank's action allows us to estimate the effect of the OMO without needing to apply econometric techniques, such as the one developed by Rigobon and Sack (2004), to account for reverse causality.

\footnotetext{
${ }^{16}$ Hendershott and Madhavan (2015) follow a similar method to account for the endogeneity of the choice of trading venue while accounting for transactions costs of U.S. Treasuries.
} 


\subsection{Estimating effect of communication of OMO volume}

The BoC publicly announces the volume and price of overnight loans taken out soon after its auction concludes. As mentioned in Section 2, during our sample period, OMOs were conducted at the overnight target rate. This makes the announcement of the price at the auction no more informative than the announcement that the BoC injected liquidity. However, any surprise in the amount of lending may provide information about the supply of and demand for funding liquidity. The rest of this section describes how we adapt the two-step methodology described in Section 3.1 to estimate the value of central bank communication of the volume of the OMO 17

The announcement of the loan volume conveys information to the market to the extent that it deviates from the expected volume. Accordingly, we use the same variables $X_{h_{o, t}^{-}}$in Section 3.1 to obtain $E\left(\mathrm{OMOVol}_{t}\right)$, the expected value of $\mathrm{BoC}$ injection of funding liquidity. Because market participants are aware of the maximum $(\overline{O M O})$ and minimum $(\underline{O M O})$ OMO size, we estimate the expectation of lending volume using the censored regression

$$
\begin{aligned}
& O M O V o l_{t}^{*}=\theta_{v}^{\prime} X_{h_{o, t}^{-}}+e_{v, t} \\
& O M O V o l_{t}= \begin{cases}0 & \text { if } O M O V o l_{t}^{*} \leq \underline{O M O} \\
O M O V o l_{t}^{*} & \text { if } 0<O M O V o l_{t}^{*}<\overline{O M O} \\
\overline{O M O} & \text { if } O M O V o l_{t}^{*} \geq \overline{O M O} .\end{cases}
\end{aligned}
$$

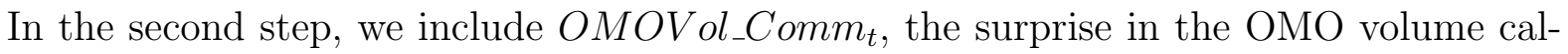
culated as the difference between the realisation of $O M O V o l_{t}$ and its expectation, in the

\footnotetext{
${ }^{17}$ As discussed in Section 2, eligible participants receive an invitation to participate in the OMO auction at 11:45 a.m., and the results of the auction are published on the external website at noon. Trading in overnight loans in this 15-minute interval is small-less than $5 \%$ of total daily volume - on days with and without liquidity injection, which limits the information revealed by overnight loan trades in this period. Our method of estimating the surprise in the volume of the OMOs makes the simplifying assumption that no funding trades occur between 11:45 a.m. and noon.
} 
following regression

$$
\Delta y_{t+1}=\alpha_{v}+\pi_{v} O M O V o l_{-} \text {Comm }_{t}+\beta_{v}^{\prime} Z_{t+1}+\epsilon_{v, t} .
$$

The announcement of the volume of funding liquidity supplied in the OMO has information content if $\pi_{v} \neq 0$.

\section{Data and sources}

Financial intermediaries use a variety of instruments to obtain funding liquidity, e.g., repos, bankers' acceptances, and commercial paper. We focus on overnight repo (short for repurchase obligation) trades primarily because they are the most important source of short-term loans in the financial system. ${ }^{18}$ Additionally, the availability of time-stamped transaction-level data on repos in Canada allows us to separate overnight loans transacted before and after the scheduled time of the OMO to accurately measure the effect of the intervention.

Repos involve the exchange of cash for securities between two entities, with the contractual obligation to reverse this exchange at a later date.19 Repos can therefore be viewed either as a loan of cash collateralised by the security or as a loan of the security against cash collateral. Some repos are motivated by the need to borrow particular securities. We exclude such so-called special repos from our sample because our focus is on the market for funding liquidity. Duffie (1996) highlights that the cash lender is willing to offer a discount on the

\footnotetext{
${ }^{18}$ The critical role short-term loans play in the financial system has been extensively studied, especially following the great financial crisis. See, e.g., Gorton and Metrick (2012), Krishnamurthy, Nagel, and Orlov (2014), Mancini, Ranaldo, and Wrampelmeyer (2016) and Boissel et al. (2017).

${ }^{19}$ We obtain the data on repo trades by matching the individual settlement instructions of these two cashfor-security trades - provided to us by the Canadian Depository for Securities (CDSX) and the Canadian Derivatives Clearing Corporation (CDCC) - to obtain the repos trades we use in our sample. Details of the algorithm used to obtain matched trades are described in Bulusu and Gungor (2020). The following copyright notice applies to the CDCC data used in this paper. "Copyright Canadian Derivatives Clearing Corporation (CDCC), all rights reserved. Not to be reproduced or redistributed. Canadian Derivatives Clearing Corporation (CDCC) disclaims all representations and warranties with respect to this information, and shall not be liable to any person for any use of this information."
} 
interest paid by the cash borrower to provide an incentive to the owners of such securities to lend them. Because our data do not include indicators of special repos, we designate repos with rate less than $95 \%$ of the overnight $\mathrm{BoC}$ target rate as special repos 20

The remaining, labelled general collateral (GC) repos, are overnight loans in which the cash lender is willing to receive any of a class of acceptable securities as collateral. GC repos are close substitutes for OMOs, which are essentially overnight loans provided by the BoC against a range of acceptable collateral. We limit our attention to repos collateralised by debt securities issued by (i) the Government of Canada (GoC), (ii) the Canada Mortgage and Housing Corporation (CMB), and (iii) Canadian provincial governments (PRV) because repos backed by other asset classes are sparsely traded.

Panel A of Table 2 shows key dependent variables for each of the three collateral classes we consider in this paper, separately for each of the levels of the overnight target rate in our sample. The dependent variables - the change in the 24-hour period after the scheduled time of the OMO $\left(h_{o, t}\right)$ of the total volume and of the volume-weighted interest rate on GC repos over the overnight target rate-are summarised using data from August 28, 2009, to December 31, 2015 21 The most regular pattern we observe is that repo volumes for all collateral types increase in the 24 hours after the BoC conducts an OMO, while they decrease in the 24 hours after 11:45 a.m. on the days it does not. For example, when the BoC target rate was $1 \%$, in the 24 hours after an OMO, GoC repo volume rose by an average of Can $\$ 870$ million. In contrast, it fell by an average Can $\$ 180$ million in the 24 hours after a non-intervention event. The spread of the repo rate over the overnight target does not exhibit a regular pattern. The GoC repo rate spread fell by $0.80 \mathrm{bps}$ and $0.05 \mathrm{bps}$, respectively, after liquidity injection when the target rate was between $0.75 \%$ and $1 \%$. While this rate spread rose by 0.57 bps after the intervention when the target rate was $0.50 \%$, only $10 \%$ of $\mathrm{BoC}$ liquidity injections in our sample were conducted at this level of the target rate. Thus,

\footnotetext{
${ }^{20}$ Our results are robust to including special repos in the analysis as well as to using different discounts on the interest rate to identify special repo trades.

${ }^{21}$ The starting date of our sample is limited by the availability of repo data at the transaction level.
} 
overall, the cost of overnight loans fell in the 24 hours after liquidity was injected through an OMO.

\subsection{Variables for forming expectations of OMOs}

Because liquidity injections are designed to alleviate aggregate liquidity shortages in the financial system, indicators of overall funding conditions are likely to help estimate the probability of OMOs. Guided by the results in Bulusu and Guérin (2019), we use predictors drawn from five sources in the first-stage estimation. Panel B of Table 2 summarises these variables for different levels of the overnight BoC target rate.

First, to account for possible persistence in liquidity conditions, we include the previous day's indicator of whether the BoC conducted an $\mathrm{OMO}$ and the volume of that operation. Second, to capture another source of persistence, we summarise the aggregate liquidity position at the end of the previous day by the cumulative balances held by market participants with access to the $\mathrm{BoC}$ lending facilities in their accounts with the $\mathrm{BoC} 2{ }^{22}$ We find that on the day before the $\mathrm{OMO}$, the average balance held at the $\mathrm{BoC}$ was greater than that on days before a non-intervention: Can $\$ 220$ million versus Can $\$ 80$ million when the target rate was $1 \%$.

Third, to get a more accurate picture of the state of the market for funding liquidity before the decision to intervene, we use the volume and rates of overnight unsecured loans and $\mathrm{GoC}$ repos in the half hour before the scheduled time of the OMO. Not surprisingly, the spread of the GoC repo rate over the BoC target rate in the half hour before $h_{o, t}$ is much greater on days with OMOs than without. When the overnight target rate was $0.50 \%$ (0.75\%), the rate spread was 4.24 bps (3.30 bps) on OMO days, compared with 0.39 bps (-0.12 bps) on days without an OMO.

Fourth, the publicly announced results of the Receiver General auctions of cash loans by

\footnotetext{
${ }^{22}$ The positions of individual firms at the $\mathrm{BoC}$ are not public information. However, we include the aggregate positions because market participants are likely to observe (a possibly noisy) signal of these quantities from their interactions with each other.
} 
the GoC that are conducted before $h_{o, t}$ are also likely to provide clues about the state of the overnight loan market. Indeed, the interest on these loans is significantly higher on the days that the BoC conducts an OMO than when it does not. The difference between the interest rate paid over the $\mathrm{BoC}$ target rate was $7.25 \mathrm{bps}, 5.45 \mathrm{bps}$ and 2.09 bps higher on OMO days compared with non-OMO days, when the target rate was $0.50 \%, 0.75 \%$ and $1 \%$, respectively. Finally, we also include market-wide indicators of financial conditions, which could summarise funding liquidity demand and supply.

\subsection{Control variables for estimating communication effect of OMOs}

The outcome variables of interest are the 24-hour change in overnight loan volumes and rates after $h_{o, t}$. Because this includes funding transactions on $t+1$ up to $h_{o, t+1}$, it is necessary to control for changing financial conditions between $t$ and $t+1$, which may affect the dependent variables. Panel $\mathrm{C}$ of Table 2 summarises these variables for the different $\mathrm{BoC}$ overnight target rates in our sample.

OMOs on day $t$ are overnight loans that must be returned to the BoC on day $t+1$. Therefore, apart from the announcement effect, we should expect $\mathrm{OMOVol}_{t}$ to affect the change in the demand for overnight loans, and possibly their price, on day $t+1$. Indeed, the loan volume allotted by the $\mathrm{BoC}$ when the target rate is $0.75 \%$ (1\%) is Can $\$ 690$ million (Can $\$ 630$ million), and the increase in GoC repo volume in the 24 hours after an OMO for the same sample is three times as high: Can $\$ 2.59$ billion (about $40 \%$ higher: Can $\$ 870$ million). Another BoC-driven source of variation in overnight funding volumes and prices that we include is the change in the overnight target rate.

To control for the variation in market conditions that could impact the dependent variables between $t$ and $t+1$, we include the changes of several indicators of financial market stress and uncertainty between these two days. We use the Canadian analogue of the London Inter-Bank Offered Rate-Overnight Indexed Swap rate (LIBOR-OIS) spread, which has been previously used in $\mathrm{Ji}(2012)$ as an indicator of distress in the funding liquidity market. 
To control for changes in economic and monetary policy uncertainty, respectively, we use the difference between $t$ and $t+1$ of the Canadian volatility (VIX) index and that of the implied volatility of options on futures of the Canadian overnight funding rate. Finally, we also include the Fontaine and Nolin (2019) estimate of limits to arbitrage inferred from the GoC yield curve, which capture funding conditions that are unrelated to the communication of the OMO.

\section{Results}

The information OMO announcements reveals about the demand for and supply of liquidity could potentially affect the price and quantity of short-term loans obtained using any of the multiple sources of funding available to financial institutions. Nevertheless, we limit our focus to overnight repos collateralised by GoC, CMB and PRV debt securities for three reasons. First, repos are the most widely used short-term funding instrument in Canada, with overnight repos accounting for more than $85 \%$ of them. Second, OMOs are effectively repos with the BoC against a range of collateral, of which the above-mentioned classes of fixed-income instruments are the most important. Finally, we have access to time-stamped transaction-level data on repos, which is essential for correctly measuring the changes in the funding rate and volume after the OMO.

We analyse the 24-hour change in the cost and volume of overnight lending after the scheduled time of the operation. Gürkaynak and Wright (2013) recommend using short windows around events to minimise the possibility that news unrelated to the event affects the outcomes of interest. The relative sparsity of overnight repo trades post $h_{o, t}$-more than $70 \%$ of repo trades are concluded before the scheduled time of the OMO announcement - as well as the presence of strong intraday patterns in funding costs (Dufour, Marra, and Sangiorgi, 2019) hampers our ability to isolate the information effect in short windows around $h_{o, t}$. Our empirical setting also makes it difficult to infer the long-run effects of information revealed by 
OMOs. Since OMOs are frequently clustered together, isolating the communication effect of any particular OMO is complicated by the variable number of events when analysing longer-horizon changes of funding cost and volume.

\subsection{Effect of OMO announcements}

Because financial market participants in Canada understand the rationale and triggers for OMOs conducted by the BoC, financial institutions that trade in the market for overnight liquidity can form coherent expectations of such operations. However, overnight loans are negotiated bilaterally, and a centralised trade reporting system does not exist. Limited preand post-trade transparency prevents institutions from observing all the information relevant to forming expectations of prevailing demand for borrowing cash and supply of lending. This friction prevents them from being able to perfectly anticipate liquidity injection by the BoC and makes OMO announcements a useful source of information about aggregate funding liquidity conditions.

To separate the effect of the increased supply of funds from that due to the information contained in OMO announcements, we begin by estimating a market-wide expectation of OMOs using the set-up described in Section 3.1. First, we use variables summarizing the demand for and supply of aggregate liquidity available until the OMO announcement $h_{o, t}$ to estimate the market-wide expectations of the operation. The results, presented in Table 3 , show that two categories of variables are significant predictors of OMOs. One set summarises the prevailing demand for funding before the auction, and the other contains information about the system-wide liquidity position at the end of the previous day. Specifically, we find that when the GoC repo rate is 1 bp higher than its mean value in the 30 minutes before $h_{o, t}$, the probability of an OMO increases by 2\%.23 Similarly, a 1-bp higher rate offered by participants borrowing cash in Receiver General auction on the day before $h_{o, t}$ makes a BoC liquidity injection event $1.7 \%$ more likely. We find that an $\mathrm{OMO}$ on the previous day predicts

\footnotetext{
${ }^{23}$ All the marginal effects described in the paper are estimated at the mean values of all the variables in the relevant sample.
} 
a $7.2 \%$ probability of liquidity injection on the day, indicating the persistence of liquidity demand and supply. When market participants hold larger balances of cash at the BoC, it indicates that liquidity is relatively plentiful because, in normal times, financial institutions are willing to accept the interest rate below the overnight target rate paid on such balances only if there is insufficient demand for borrowing cash. We find that this intuition holds in the data: A Can $\$ 1$ billion larger cumulative balance at the end of the previous day predicts that the probability of liquidity injection on the current day is $3.2 \%$ lower.

Second, we estimate the information revealed by the OMO announcement, OMO_Comm, which stems from errors in the market's forecast of liquidity injection. The absence of an OMO when one is highly expected leads the market to revise its expectation of the demand for funding liquidity downwards. In such circumstances, OMO_Comm could take negative values. In contrast, the announcement of an OMO when the probability assigned to it is low should lead to an upward revision in the expected overnight loan demand, which translates to a larger and more positive value of OMO_Comm.

The coefficient of OMO_Comm is positive and significant for GoC and CMB repos in Panel A of Table 4, meaning that an unexpected OMO raises the cost of borrowing through overnight repos collateralised by fixed-income instruments belonging to these security classes. A surprise intervention leads the market to recognise that the need for aggregate funding liquidity is greater than previously expected, and cash lenders react by raising the price of overnight loans. Also note that the coefficient of the volume of liquidity injected in an $\mathrm{OMO}$ is negative and significant for GoC repo rates, reflecting the fact that OMOs influence overnight interest rates though the supply channel. Indeed, the cost of borrowing using GoC repos falls by an average 0.5 bps per Can $\$ 1$ billion supplied by the BoC. We find that this effect is localised to GoC repos and does not significantly reduce the cost of borrowing cash against CMBs and PRVs.

To interpret the magnitude of the supply and information effects of OMOs on overnight borrowing rates, consider the days on which an OMO was conducted even though the ex- 
pected probability of $\mathrm{BoC}$ lending was less than $33 \%$. The average rise in the cost of overnight borrowing against GoCs and $\mathrm{CMBs}$ in the 24 hours after the OMO on such days due to the market updating its beliefs about the demand for funding liquidity was 59.4 bps and 105.5 bps, respectively. The average 24-hour change in GoC and CMB overnight repo rates on these days was $24.2 \mathrm{bps}$ and $64.0 \mathrm{bps}$, respectively. Thus, the supply of funding by the $\mathrm{BoC}$ in this subsample reduced the cost of borrowing using these two instruments by 35.2 bps and 41.5 bps, respectively. The average fall in overnight GoC and CMB repo rates was 48.0 bps and 85.3 bps, respectively, on days when liquidity injection was expected with greater than $67 \%$ probability but the BoC did not conduct an OMO. Not surprisingly, borrowing rates change little in response to the announcement of OMOs on days when they are largely expected. For example, the average GoC and $\mathrm{CMB}$ overnight repo rate fell by $2.5 \mathrm{bps}$ and $4.5 \mathrm{bps}$, respectively, when no OMOs were announced on days with less than $33 \%$ expected probability of an operation.

Note that the statistical significance of the coefficient of OMO_Comm confirms the information value of OMO announcements. Because the magnitude of OMO_Comm is not easy to interpret, we use the $33 \%$ and $67 \%$ cut-off values for expected probability of an OMO only to help provide guidance about the economic magnitude of the information effect.

As another way to compare the relative importance of the drivers of the changes in overnight borrowing rates, we run the regression specified in equation (2) using standardised dependent and independent variables. In results (not reported in this paper), we find that the communication effect of OMOs is greater than the drop in borrowing rates due to the additional liquidity injected. A change of one standard deviation (sd) in the information revealed by an OMO leads to a $0.17 \mathrm{sd}(0.20 \mathrm{sd})$ change in the $\mathrm{GoC}(\mathrm{CMB})$ repo rate, which is greater than the $0.12 \mathrm{sd}$ (statistically insignificant) change in the GoC (CMB) repo rate due to a 1-sd change in the volume of lending by the BoC. Taken together, OMO communication and supply effects explain $2 \%$ (3\%) of the 24-hour change in the GoC (CMB) repo rate after the scheduled time of the operation; no other variable that we consider has a statistically 
significant impact 24

Panel B of Table 4 shows that the information content in an OMO announcement has no impact on the volume of overnight borrowing. However, every Can $\$ 1$ of liquidity the BoC injects results in the GoC repo volume rising by Can $\$ 1.60$ in the 24 hours after the OMO. We find that OMO announcements affect the price but not the volume of liquidity, which is consistent with market participants offering all their surplus funds on each day at the prevailing rate - because there is no benefit of withholding liquidity when the interest rate is even marginally higher than the deposit rate.

\subsection{Effect of OMO volume announcement}

To ascertain the ability of market participants to learn from announcements of OMO volume, we begin by estimating the quantity of funding liquidity expected to be taken up at the auction, using the censored regression specification of equation (3). Because we purge our sample of days on which the BoC withdraws liquidity (see footnote 15 for details), the lower bound $\underline{O M O}$ is set to zero. The maximum quantity of lending by the BoC in an OMO during our sample was Can $\$ 1.5$ billion. However, on three days in our sample, the BoC conducted two OMOs (the first earlier than 11:45 a.m.); we therefore set the upper bound $\overline{O M O}$ to $\mathrm{Can} \$ 3$ billion 25

Table 5 shows that the variables that are useful for predicting an OMO continue to be valuable in forming expectations about the volume of liquidity injected. The persistence of funding liquidity conditions is highlighted by the fact that the volume and occurrence of an operation as well as the total balance held at the BoC on the previous day significantly predict the volume of intervention on the day. An operation on day $t-1$ increases the expected quantity of liquidity supplied on $t$ by Can $\$ 594.7$ million. Further, every Can $\$ 1$ the

\footnotetext{
${ }^{24}$ Neither the volume of liquidity injected nor the information revealed by OMO announcements has a statistically significant impact on PRV repos, suggesting that they are imperfect substitutes for the main sources of funding liquidity. Indeed, Bulusu and Guérin (2019) show that PRV repo rates and haircuts do not move closely with those of GoC and CMB repos.

${ }^{25}$ Our results are nearly identical if we drop the three days with two liquidity injections each and set $\overline{O M O}$ to Can $\$ 1.5$ billion.
} 
$\mathrm{BoC}$ injects in an operation on day $t-1$ leads to an anticipated Can $\$ 0.37$ loan on day $t$. Finally, the predicted volume of the operation falls by Can $\$ 0.33$ for every additional Can $\$ 1$ deposited at the $\mathrm{BoC}$ by eligible participants at the end of $t-1$. The conditions prevailing in the funding market before the scheduled time of the OMO are the other critical inputs that help form expectations of $\mathrm{BoC}$ lending volume: a 1 bp higher rate of $\mathrm{GoC}$ repos ( $\mathrm{GoC}$ cash auctions before the OMO) increases OMO volume by Can $\$ 179.9$ million (Can $\$ 151.1$ million).

The results of the second-stage regression specified in equation (44), summarised in Table 4 . are in broad agreement with the conclusions from the analysis of OMO announcements. Specifically, we see that every Can $\$ 1$ billion higher-than-expected volume at the auction leads to an 18.3 bps and 27.8 bps increase, respectively, in the GoC and CMB repo rates in the 24 hours after the scheduled time of the operation. This reaction is consistent with market participants adjusting their expectations of aggregate funding demand upwards in response to a surprisingly large liquidity injection. Consistent with the results in Table 4 , a surprise in OMO volume does not lead to changes in either the PRV repo rate or the volume of overnight repos collateralised by GoCs, CMBs or PRVs (see Panel B).

At first glance, it may be surprising that the coefficient of $O M O V o l$ is neither negative nor significant in Panel A of Table 6. This appears inconsistent with the conclusions from the second-stage regression of the $\mathrm{OMO}$ announcement effect: that $\mathrm{BoC}$ liquidity injection reduces the cost of overnight lending. However, note that the surprise OMOVol_Comm is measured as the difference between the expected and realised OMO volume and therefore includes the term -OMOVol. This prevents us from interpreting the coefficient of $O M O V o l$ in Table 6 as the impact of $\mathrm{BoC}$ lending on the change in the overnight lending rate and volume in the 24 hours after the operation.

Our analysis of the information content of OMO volume announcements reinforces the message that the market learns about funding conditions from public announcements of liquidity injection by the $\mathrm{BoC}$ and appropriately adjusts the price of liquidity to reflect this information. Central bank announcements of OMOs mitigate the desired impact of 
the increased supply of cash to the financial system. Nevertheless, to answer the question posed in the title of the paper: Communication of OMOs is valuable because it improves the informativeness of the price of overnight loans, which is desirable because it is a key input into the decision-making process of all agents in the economy.

\section{Communication of central bank SLOs}

Thus far, we have demonstrated - in the context of OMOs - that central bank communication helps financial institutions learn about the underlying conditions in markets characterised by limited information dissemination. We now establish the generality of the information value of announcements of central bank operations in OTC markets - as well as the robustness of our empirical methodology—by extending our analysis to SLOs, used to lend government securities when their borrowing cost is judged to be high enough to impair the normal functioning of financial markets.

Central banks pay close attention to this market due to the critical role it plays in financial intermediation. Baklanova et al. (2019) highlight the large size of this market and its centrality to raising funding liquidity (also see Aggarwal, Bai, and Laeven (2020) in this context). Fontaine, Garriott, and Gray (2016) point out that dealers rely on being able to borrow bonds to meet customer demand and thus provide market liquidity without incurring the costs associated with carrying inventories of various debt securities 26 Additionally, securities-borrowing trades support short-selling activity, which facilitates price discovery of government debt-used as a benchmark to price all risky assets in the economy. Central banks lend government securities to the financial market to counteract the adverse effects on financial stability due to a sharp rise in demand or a fall in their supply ${ }^{27}$

\footnotetext{
${ }^{26}$ Note that delivery conventions in the bond market prevent buyers from obtaining possession of bonds on the day of the transaction. Securities-lending trades are settled on the same day and therefore allow for greater flexibility in providing market-making services.

${ }^{27}$ The Federal Reserve Bank of New York lends U.S. Treasuries overnight to offer "a secondary and temporary source of these securities to the financing market [...] to provide smooth clearing" of these instruments. The BoC operates an overnight lending facility to "support the liquidity of GoC securities
} 
OMOs and SLOs undertaken by the BoC share key operational features, which makes the empirical strategy described in Section 3 (with minor modifications detailed in Section 6.1) appropriate for analysing the SLO announcement effect. First, the market for borrowing securities is negotiated bilaterally, with limited pre- and post-trade transparency. Thus, BoC SLO announcements are a valuable source of information about the aggregate supply and demand conditions in the bond borrowing market. As with OMOs, the BoC does not possess superior information about securities borrowing but makes its decision on whether to undertake an SLO by aggregating information gleaned from confidential bilateral discussions with key financial institutions.

Second, both the threshold and timing of intervention are publicly known. During our sample period, at 11:00 a.m., the $\mathrm{BoC}$ communicates to eligible participants the decision to hold an auction for a security whose borrowing fee was at least $50 \%$ of the overnight target. The results of the SLO - specifically, the identity of the security and the volume and average price of lending - are published on the BoC's external website soon after the auction concludes at 11:15 a.m.28

Finally, the market is also aware that the maximum quantity of a security on offer at the SLO is $50 \%$ of the BoC's holdings of the security. Given that this was far greater than the demand at the auction, the price paid at all but one SLO in our sample was equal to the minimum bid rate, i.e., $50 \%$ of the overnight target rate. Thus, only the announcement of the SLO and the volume loaned out are informative about the underlying conditions for borrowing the bond 29

by providing a secondary and temporary source" of such assets. The Bank of Japan uses SLOs for similar reasons. For details of these operations, see the relevant websites of the Federal Reserve Bank of New York, Bank of Japan and the Bank of Canada. The European Central Bank's securities lending programme is closer in spirit to the Term Securities Lending Facility in the United States: these loans are of longer duration and are designed to allow dealers to fund themselves by swapping lower-quality for safer collateral (please click here for the relevant website).

${ }^{28} \mathrm{On}$ the days when the BoC makes interest-rate announcements, eligible participants are notified about the auction at 11:45 a.m., and results are published immediately after its conclusion at noon; click here for the website containing further details.

${ }^{29}$ Many of these features are shared with SLOs conducted by other major central banks. For example, the Federal Reserve Bank of New York conducts an auction for overnight loans of the securities in its System Open Market Account at 12:15 p.m., with the reserve price set at 5 bps. Similarly, the securities-lending 


\subsection{Methodology}

We estimate the communication effect of SLOs using a procedure similar to that followed for OMOs, with adjustments for the fact that multiple events (and non-events) can occur on the same day. Each security $i$ of the set of unmatured GoC bonds $I_{t}$ on day $t$ is potentially subject to an SLO at the pre-announced time $h_{s, t}$ (common to all $i$ ). For each security $i$, market participants observe the vector $X_{h_{s, t}^{-}}^{i}$ just before $h_{s, t}$, which they use to form expectations of the latent variable $v_{t}^{i}, E\left(v_{t}^{i}\right)=\kappa^{\prime} X_{h_{s, t}^{-}}^{i}$. The difference between the realisation of the latent variable and its expectation is given by $\zeta_{t}^{i}=v_{t}^{i}-E\left(v_{t}^{i}\right)$. The BoC conducts an SLO in security $i$ if $v_{t}^{i}$, the difference between the overnight borrowing fee for the security and the threshold fee (common to all $i$ on a given date $t$ ), is non-negative.

The literature suggests that the demand for borrowing specific securities is primarily driven by bond-specific characteristics and cannot typically be substituted by borrowing other bonds. For example, Vayanos and Weill (2008) argue that security-specific borrowing demand gives rise to the increased liquidity and borrowing activity in newly issued U.S. Treasuries. Accordingly, we impose the additional assumption that errors $\zeta_{t}$ are independent across securities on a given day 30

Following the discussion in Section 3.1, in the first step, the communication value of an $\mathrm{SLO}$ (or the absence of an SLO) for security $i$ on day $t$ can be summarised by the conditional expectation of the error in the forecast of the borrowing fee over the target rate:

$$
S L O \_C o m m_{t}^{i}=\left\{\begin{array}{l}
E\left(\zeta_{t}^{i} \mid S L O I n d_{t}^{i}=0\right)=\rho \frac{-\phi\left(\kappa^{\prime} X_{h_{s, t}^{i}}^{i} / \rho\right)}{1-\Phi\left(\kappa^{\prime} X_{h_{s, t}^{i}}^{i} / \rho\right)} \\
E\left(\zeta_{t}^{i} \mid S L O I n d_{t}^{i}=1\right)=\rho \frac{\phi\left(\kappa^{\prime} X_{h_{s, t}^{i}}^{i} / \rho\right)}{\Phi\left(\kappa^{\prime} X_{h_{s, t}^{i}}^{i} / \rho\right)},
\end{array}\right.
$$

facility at the Bank of Japan is triggered in the afternoon when "more than two counterparties request" it. The borrowing fee is set at a level that incentivises trading between market participants over borrowing from the Bank of Japan.

${ }^{30}$ To account for the possibility that the variance of the errors may depend on bond types, we also estimate the parameters of the expectation-formation stage on subsamples of bonds; see Section 6.3.1 for details. 
where $\kappa$ is replaced by $\hat{\kappa}$, obtained by estimating the pooled probit model $S L O I n d_{t}^{i}=1$ if $\kappa^{\prime} X_{h_{s, t}^{-}}^{i}+\zeta_{t}^{i} \geq 0$ and SLOInd $d_{t}^{i}=0$ if $\kappa^{\prime} X_{h_{s, t}^{-}}^{i}+\zeta_{t}^{i}<0$.

We then use a pooled regression for all securities $i$ on all days in the sample to estimate $\lambda$ in

$$
\Delta w_{t+1}^{i}=\delta+\lambda S L O \_C o m m_{t}^{i}+\gamma^{\prime} U_{t+1}^{i}+\nu_{t}^{i}
$$

and test the hypothesis that $\lambda \neq 0$ to establish the presence of a communication effect of SLOs. Here, the dependent variables $\Delta w_{t+1}^{i}$ are the change in the (i) overnight borrowing fee, and (ii) volume of overnight borrowing of security $i$ in the 24-hour period after $h_{s, t}$ (compared with the corresponding value in the 24 hours before $\left.h_{s, t}\right) . U_{t+1}^{i}$ is the vector of control variables that could affect $\Delta w_{t+1}^{i}$, independently of SLO_Comm ${ }_{t}^{i}$.

Following the discussion in Section 3.2, we estimate the expected SLO volume for security $i$ on date $t$ using the censored regression

$$
\begin{aligned}
& S L O V o l_{t}^{i *}=\quad \kappa_{v}^{\prime} X_{h_{s, t}^{-}}^{i}+v_{v, t} \\
& S L O V o l_{t}^{i}= \begin{cases}0 & \text { if } S L O V o l_{t}^{i *} \leq 0 \\
S L O V o l_{t}^{i *} & \text { if } S L O V o l_{t}^{i *}>0 .\end{cases}
\end{aligned}
$$

The lower bound of zero reflects the practice that the BoC does not borrow government securities from the market using SLOs. During the sample period, the BoC set the maximum lending in a security to $50 \%$ of its holdings of that security. Because this bound was never breached in our sample, we ignore the variation in the upper bound of SLOs across securities over time for simplicity. We estimate $\kappa_{v}$ by pooling the events and non-events for all bonds for the active sample ignoring the possible right-censorship of SLOVol. In the second step, we

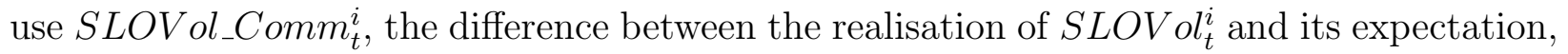
in the pooled regression

$$
\Delta w_{t+1}^{i}=\delta_{v}+\lambda_{v} S L O V o l_{-} C o m m_{t}^{i}+\gamma_{v}^{\prime} U_{t+1}^{i}+\nu_{v, t}^{i}
$$


and test whether $\lambda_{v}=0$ to establish the value of communicating the volume of the SLO.

\subsection{Data and sources}

Government bonds are typically borrowed either using repos or from securities-lending agents who lend them for a fee on behalf of the owners of these securities. While we restrict our attention to the repo market because we do not have access to time-stamped transactionlevel data from securities lenders, Bulusu and Gungor (2020) show that borrowing fees are similar in both these markets that perform the same economic function. From the perspective of the borrower of the security, the borrowing fee for the security is the difference between the interest that could have been earned on the cash if the borrower were willing to accept any security, i.e., the $\mathrm{GC}$ repo rate, and the (lower) rate that the borrower is willing to receive on the cash to induce the holder of the desired security to post it as collateral.

Because the $\mathrm{GC}$ repo rate hovers around the $\mathrm{BoC}$ overnight target rate, we measure the borrowing fee as the difference between the overnight BoC target rate and the rate on repos collateralised by the security. (See Table 7 for the description of all the variables and their sources used for analysing the impact of SLO announcements.) Restricting our attention to special repos would result in a substantial reduction of our sample size because only a subset of bonds traded are on special on any given day. We therefore include both overnight GC and special repos in our analysis. We confirm that our results are robust to using only special repos to calculate the change in borrowing fee and volume.

Panel A of Table 8 shows the average change in borrowing fees and volume in the 24 hours after the scheduled time of an SLO announcement for GoC bonds with two (2Y), five (5Y) and ten $(10 \mathrm{Y})$ years to maturity when they were first issued ${ }^{31}$ We see no discernible pattern

\footnotetext{
${ }^{31}$ We exclude other GoC debt securities because, in our sample, only four SLOs were undertaken to lend GoC bills (securities with maturity at issue less than one year) and no GoC bonds with 30 or 50 years to maturity were involved in BoC operations. Further, we purge our sample of the following: 2-year bonds with less than 0.15 years to maturity or first issued less than 0.05 years ago; 5 -year bonds with less than 0.05 years to maturity or first issued less than 0.35 years ago; and 10-year bonds with less than 1.5 years to maturity or first issued less than 0.50 years ago. This is because, in our sample, no 2-year, 5 -year and 10-year bond with less than 0.21, 0.09 and 1.93 years to maturity, respectively, was involved in an SLO. Similarly,
} 
of borrowing fees and volumes between bonds that are involved in SLOs and those that are not. In some cases, the borrowing fee even rises after the $\mathrm{BoC}$ temporarily increases the availability of the bond through SLOs. However, as we show in Section 6.3.2, this is not a reflection of the effectiveness of SLOs. We find that the communication of SLOs counterbalances - and sometimes even overturns - the strong reduction in borrowing fees due to the increased supply of the bond through SLOs.

\subsubsection{Variables for forming expectations of SLOs}

As in the case of OMOs, our inability to observe individual financial institutions' information sets leads us to construct market-wide expectations of an SLO announcement and lending volume in each bond. The volume and fee for borrowing individual securities before the scheduled time of the SLO are natural candidates for forming expectations of intervention. Indeed, we document, in Panel B of Table 8, that borrowing fees before the SLO for bonds loaned out by the BoC are significantly higher than those not involved in the intervention. Before $h_{s, t}$, the average fee to borrow the $5 \mathrm{Y}(10 \mathrm{Y})$ bond loaned out by the BoC was 42.7 bps (40.4 bps), compared with 4.0 bps (9.3 bps) for those $5 \mathrm{Y}$ (10Y) bonds not involved in the operation. To account for possible persistence of borrowing demand, we include the cumulative lending volume and the number of interventions by the $\mathrm{BoC}$ in the bond up to (but not including) the current day.

Since the BoC's stated policy is to use SLOs to alleviate undesirable shortages in the market for borrowing GoC securities, we use indicators of borrowing demand and supply in the expectations-formation stage. The supply of GoC securities is limited by their amount outstanding less that locked up in alternative uses Corradin and Maddaloni, 2020; D'Amico, Fan, and Kitsul, 2018). Panel B of Table 8 confirms that - with the exception of $5 \mathrm{Y}$ bonds

no 2-year, 5-year and 10-year bonds with less than 0.07, 0.41 and 0.67 years of age were loaned out by the BoC. The rationale for applying these filters is the assumption that the market perfectly anticipates that such bonds would not feature in SLOs and thus does not glean any information from non-events. Including them would only induce error in our estimation of market expectations of SLOs. Nevertheless, our results are qualitatively unchanged when including all 2-year, 5-year and 10-year bonds. 
when the $\mathrm{BoC}$ target rate was $0.50 \%$ - the average outstanding amount of bonds loaned by the $\mathrm{BoC}$ was lower compared with bonds not loaned by the $\mathrm{BoC}$ with the same original time to maturity. The effective supply of bonds may be reduced by buy-and-hold investors who may not be willing to lend the bond. We proxy for this effect using the holdings of GoC securities by non-Canadian official institutions 32 When the BoC overnight target rate was $1 \%$, the official sector held an average of Can $\$ 1.9$ billion of $5 \mathrm{Y}$ bonds involved in, and Can $\$ 1.5$ billion of $5 \mathrm{Y}$ bonds not involved in, the SLO. This pattern was true for all bonds except for $2 \mathrm{Y}$ bonds when the target rate was $1 \%$. An alternative source of GoC bond supply is the bonds available for borrowing through securities lending agents. We would expect that SLOs are more likely for bonds with limited supply available at these agents. This is true in the data: The average fraction of bonds on offer that have been borrowed from securities lenders is larger for the SLO sample. Utilisation rates on SLO bonds are above $95 \%$ in most cases, while none of the non-SLO bonds has more than $90 \%$ of their available supply taken up.

Government bonds are borrowed for one of three principal reasons: market making, hedging or speculation. Market makers attempt to hedge the interest-rate risk arising from their holdings of debt securities by borrowing and short selling, government bonds Graveline and McBrady, 2011; Rydqvist and $\mathrm{Wu}, 2016$ ). As a proxy for their holdings of such bonds, we use their inventories of GoC bonds, about which financial market participants provide information to the BoC as a condition for participating in auctions of GoC securities. Market makers also hedge anticipated inventories from proximate $\mathrm{GoC}$ bond issues; we therefore include the pre-announced size and time of such auctions as predictors of SLOs

Both hedgers and speculators trade government bond futures to take positions on interestrate risk. Because the delivery of any of an acceptable basket of bonds can be used to close

\footnotetext{
${ }^{32}$ While we use confidential BoC data to obtain these estimates, this variable can be interpreted as a noisy proxy of the true passive holdings that other market participants may be able to infer from, e.g., their trading activities.

${ }^{33}$ See Berger-Soucy, Garriott, and Usche (2018) for details about the issuance practices of GoC securities. Dealers may also borrow securities to fulfill customer orders. However, we do not have information about this source of borrowing demand.
} 
a short position in the futures market, we use indicators of whether a bond is deliverable against such contracts for estimating the probability of an SLO. For example, we see that $98 \%(35 \%)$ of $2 \mathrm{Y}$ bonds that are deliverables are loaned (not involved) in SLOs when the BoC target rate was $1 \%$. We supplement these predictors with market-wide indicators that could drive hedging and speculative demand: the spread between the yield on bonds issued by (i) the provincial government of Ontario, and (ii) commercial paper issued by highly rated corporations in Canada over the yield on GoC bonds of the corresponding maturity. Finally, in accordance with the results in D'Amico, Fan, and Kitsul (2018) and Bulusu and Gungor (2020) that borrowing demand varies with its age, we also see that, on average, SLOs are conducted on older bonds.

Table 9 summarises the 568 SLOs conducted by the BoC in our sample, which spans the period from August 28, 2009, to December 31, 2015. SLOs were infrequent occurrences before 2013: $96 \%$ of SLOs occurred in the last two years of our sample period. About 1.6 dealers participated in each SLO and borrowed Can $\$ 112$ million on average. The borrowing fee was exactly equal to the trigger for the SLO, or $50 \%$ of the BoC overnight target rate, in all but one SLO in our sample.

\subsubsection{Control variables for estimating communication effect of SLOs}

Analogous to the analysis of OMOs, our dependent variables are the 24-hour change in borrowing fees and volume after $h_{s, t}$. To purge the changes in borrowing volume and fees post-intervention that are unrelated to the announcement of the SLO, we control for both bond-specific and market-wide changes between $t$ and $t+1$ that could affect these outcomes.

The allotment size of a bond in the SLO could affect the borrowing demand the next day, when the bonds need to be returned to the BoC. We also include drivers of changes in supply of and demand for borrowing the bond arising from an abundance of caution, despite the fact that these may also be affected by the announcement of the operation. In particular, we include the outstanding amount of the bond, its holdings by official (non-BoC) institutions, 
its change in benchmark status, and the change in the open interest in futures contracts against which the bond is deliverable. From Panel $\mathrm{C}$ of Table 8, we see that the increase in official holdings of bonds loaned out by the BoC is larger than that of those not involved in the SLO.

To account for market-wide changes in supply and demand, we also include changes to the $\mathrm{BoC}$ overnight target rate, the yield spread of bonds issued by the provincial government of Ontario as well as that of highly rated commercial paper over the GoC zero-coupon rates on bonds with equivalent time to maturity.

\subsection{Results}

To account for the possibility that the strength of the determinants considered in this paper varies by bond type, we perform the analysis both for the full sample and for selected subsets based on relevant bond characteristics. As discussed previously, only 2Y, 5Y and $10 \mathrm{Y}$ bonds are involved in $\mathrm{BoC}$ operations. Given the literature on the varying preference for maturity by investor type (Greenwood and Vayanos, 2010), we analyse bonds of these three maturities to control for potential clientele effects ${ }^{34}$ As has been established in the literature, benchmarks (or on-the-runs) are the most-actively traded bonds at every maturity, and postbenchmarks experience significantly lower liquidity (Bulusu and Gungor, 2020; Vayanos and Weill, 2008). We therefore separately analyse benchmark and post-benchmark bonds. ${ }^{35}$

\subsubsection{Expectation of SLOs}

Table 10 reports the results of the probit model for predicting $\mathrm{BoC}$ securities lending operations for chosen sub-samples of the data. A strong predictor of BoC lending in a bond is the borrowing fee before the scheduled time of the SLO. This is not surprising because

\footnotetext{
${ }^{34}$ We also analyse sub-samples based on time remaining to maturity. In particular, we divide all bonds into three duration buckets: less than three years, three to seven years, and more than seven years to maturity, and we obtain similar results.

${ }^{35}$ Since, as shown in Table 9 there is only one event involving a pre-benchmark bond, the non-benchmark sample consists almost entirely of post-benchmark bonds.
} 
the operation is triggered when the borrowing fee is at least $50 \%$ of the overnight target rate. A borrowing fee 100 bps greater than the average increases the expected probability of lending in the bond by $2.0 \%$. This probability also increases by $0.1 \%$ if the volume of repos collateralised by the bond decreases by Can $\$ 1$ billion before $h_{s, t}$, which indicates lower availability of the bond for borrowing. We also find evidence for persistence in borrowing demand: An increase in the previous day's SLO volume by Can $\$ 100$ million predicts a $0.3 \%$ higher probability of an SLO on the day.

We confirm that indicators of borrowing demand and supply identified in the literature on the drivers of repo specialness are significant in predicting BoC operations in a security Corradin and Maddaloni, 2020; D'Amico, Fan, and Kitsul, 2018; Fleming and Garbade, 2007). Bonds with larger effective supply have lower probability of experiencing BoC operations. An increase of Can $\$ 10$ billion in a bond's outstanding amount and a decrease of Can $\$ 1$ billion in the amount of it held by foreign official investors decreases the probability of BoC lending in the bond by $6.1 \%$ and $0.2 \%$, respectively. Similarly, a $10 \%$ decrease in the utilisation (defined as the ratio of a security on loan to the total available for lending) of a bond in the private securities lending market results in $0.1 \%$ lower probability of the BoC lending the bond. In addition, we find that activity in the futures market influences the demand for borrowing the bond. Concretely, a bond that can be used to settle a futures contract has a $0.3 \%$ higher probability of BoC lending.

There is significant variation in the importance of the supply and demand factors across the different sub-samples. The marginal impact of most factors is lowest for $2 \mathrm{Y}$ bonds and tends to increase with the bond's maturity at issue. For example, 2Y, 5Y and 10Y bonds that are deliverable against futures contracts have higher BoC lending probability of $0.1 \%$, $0.3 \%$ and $0.4 \%$, respectively. A Can $\$ 1$ billion increase in the amount outstanding of a $2 \mathrm{Y}$ bond has a negligible consequence on its being loaned out, while an equivalent increase in the amount outstanding of $5 \mathrm{Y}$ and $10 \mathrm{Y}$ bonds decreases their probability of BoC operation by $0.1 \%$ in both cases. An decrease in repo rate of $1 \mathrm{bp}$ before the scheduled time of operations 
increases the probability of lending in $2 \mathrm{Y}$ bonds by only $0.3 \%$, compared with an increase of $2.4 \%$ and $2.1 \%$, respectively, for $5 \mathrm{Y}$ and $10 \mathrm{Y}$ bonds. This is consistent with the lower ex ante probability of $\mathrm{BoC}$ lending in two-year bonds: Only 43 of the 568 operations in our sample period involve bonds with two years to maturity at issue.

The borrowing fee before the scheduled time of the SLO continues to be an important predictor of lending for benchmark as well as post-benchmark bonds. A borrowing fee that is 10 bps higher increases the probability of $\mathrm{BoC}$ operations in benchmarks (post-benchmarks) by $0.5 \%(0.1 \%)$. Another useful predictor of $\mathrm{BoC}$ lending in a post-benchmark bond is its utilisation in the private securities-lending market. A $1 \%$ increase in the utilisation of securities available on loan increases the probability that the bond would be loaned out by the $\mathrm{BoC}$ by $0.6 \%$. In contrast, this has a negligible impact on the probability of a securities lending operation in a benchmark bond. These results are consistent with the findings in Bulusu and Gungor (2020), who show that benchmark bonds are borrowed using repos, while post-benchmark lending is concentrated in the private securities-lending market.

Predictors of SLOs are also useful for forecasting the volume of lending by the BoC, with the main exception of utilisation in the securities lending market. As seen in Table 11, which summarises the results of the censored regression specified in equation (7), the prevailing cost of borrowing the bond before $h_{s, t}$ and the previous lending in the bond are significant predictors of SLO volume in all the sub-samples we analyse. A 1-bp higher fee predicts an average of Can $\$ 1.7$ million larger SLO volume; this effect ranges from Can $\$ 1.8$ million for $10 \mathrm{Y}$ bonds to Can $\$ 6.8$ million for $2 \mathrm{Y}$ securities. BoC lending volume is also persistent: the average GoC security with Can $\$ 1$ higher-than-average BoC lending on the previous day is expected to experience a Can $\$ 0.5$ larger SLO volume on the day (between Can $\$ 0.3$ for $2 \mathrm{Y}$ bonds and Can $\$ 0.8$ for post-benchmarks).

While none of the other variables mentioned previously that predict SLOs is useful for forming expectations of SLO volume in the $2 \mathrm{Y}$ bond, they continue to be informative for other bond types. Lower amounts outstanding, as well as larger holdings of inactive institu- 
tional investors, increase the expected lending volume. Overall, BoC lending in bonds with Can $\$ 1$ billion more outstanding (owned by passive investors) is lower by Can $\$ 30$ million (higher by Can $\$ 180$ million), with the marginal impact being higher for benchmark than for post-benchmark bonds. $5 \mathrm{Y}$ and $10 \mathrm{Y}$ bonds that are eligible to be delivered to settle open futures contracts experience an average of Can $\$ 24.9$ million and Can $\$ 27.7$ million, respectively, of lending through SLOs. The substantially lower goodness-of-fit measure of the regressions predicting SLO volume, however, suggests that market participants are rather more accurately able to estimate the SLO in a bond than the amount of lending at the operation.

\subsubsection{SLO communication effect}

Table 12 summarises the results of the second-stage regression shown in equation (6). First, in Panel A, we see that the increase in supply by the BoC has the desired effect. The fee to borrow the average GoC bond falls by 20.0 bps in the 24 hours after Can $\$ 1$ billion of it is taken up at the SLO auction. The drop of 20.6 bps for borrowing a post-benchmark bond is larger than the 16.7 bps fall in lending fee for benchmark bonds when Can $\$ 1$ billion is loaned by the BoC. The impact of a Can $\$ 1$ billion supply monotonically increases with the maturity of the bond at issue: from a statistically insignificant amount for $2 \mathrm{Y}$ bonds, to 16.2 bps and 23.2 bps, respectively, for $5 \mathrm{Y}$ and $10 \mathrm{Y}$ bonds.

$S L O \_C o m m_{t}^{i}$ can be viewed as the revision to the net demand for borrowing bond $i$ on day $t$. To see this, following the discussion of the variable OMO_Comm in Section 3.1, note that SLO_Comm $m_{t}^{i}$ takes a lower value for bonds $i$ not involved in an operation. (Indeed, it can be negative when an SLO was expected with high probability but did not materialise.) This leads to the market lowering its estimate for the net demand to borrow security $i$ on day t. The positive and significant coefficient of SLO_Comm in all the sub-samples in Panel A shows that unexpected lending in a bond leads the market to revise upwards its estimate of borrowing demand, which increases the fee charged by lenders in the 24 hours after the SLO 
announcement.

SLO_Comm $m_{t}^{i}$ depends on the outcome SLOInd $d_{t}^{i}$ as well as the predictors $X_{h_{s, t}^{-}}^{i}$, and its magnitude cannot be interpreted easily. To understand the size of the SLO communication effect, consider the case of bonds that were involved in an SLO, but whose expected probability of BoC lending was below 33\%. The borrowing fee for such bonds rose by an average of 11.9 bps in the 24 hours after the announcement due to the information revealed by it. The total borrowing fee for these same bonds increased by an average of $6.4 \mathrm{bps}$ in the same period, implying that the higher supply due to the SLO moderated the information effect to a tune of $5.5 \mathrm{bps}$. At the other end of the spectrum, the lack of an SLO for bonds with expected lending probability of over $67 \%$ resulted in the average lending fee decreasing by $9.7 \mathrm{bps}$ in the 24 hours after the scheduled time of the announcement. In accordance with the intuition that the information revealed by highly anticipated SLOs occurring is small, we find that the lending fee rises by only 1.7 bps due to SLO announcements in bonds with expected probability over $67 \%$. Similarly, the borrowing cost falls by a marginal 0.1 bps in the 24 hours after $h_{s, t}$ for bonds without an operation that the market judged to be loaned out by the BoC with probability of less than $33 \%$.

Note that our conclusion about the information content of SLO announcements is based on the statistical significance of the coefficients of SLO_Comm in Panel A of Table 4 . We use the sample split by the expected probability of SLOs only to gain an understanding of the magnitude of the announcement effect. Using the same cut-offs to compare the results for different types of bonds, we find that the borrowing fee for the most unexpected SLOs - those with expected probability of operation under 33\% - in benchmark bonds rises by 9.8 bps, less than the 12.8 bps increase observed for non-benchmarks. This effect also increases with the maturity of the bonds at issue: $9.5 \mathrm{bps}, 11.0 \mathrm{bps}$ and $12.6 \mathrm{bps}$, respectively, for the most unexpected SLOs of $2 \mathrm{Y}, 5 \mathrm{Y}$ and $10 \mathrm{Y}$ bonds. Thus, an unanticipated SLO announcement raises by more the cost of borrowing bonds that are held in larger proportion by the lessactive and longer-horizon investors. 
To compare the relative importance of the communication of these operations, we run the second-stage regression in equation (6) after standardizing all the dependent and independent variables except the change in the bond's benchmark status. Results (not reported here) show that, amongst the variables we study, the information revealed by SLO announcements has the largest effect on the change in the borrowing fees post the SLO for all but $2 \mathrm{Y}$ bonds. A 1-sd increase in SLO_Comm raises the borrowing fee by about $0.2 \mathrm{sd}$ for all bond types, with the exception of $2 \mathrm{Y}$ bonds for which the corresponding value is $0.1 \mathrm{sd}$. For the non- $2 \mathrm{Y}$ bonds, this is more than twice as large as the effect of any other control variable. For $2 \mathrm{Y}$ bonds, the effect of the announcement is about $20 \%$ smaller than that due to the change in the overnight target rate but at least twice as large as any other variable. Thus, we not only find that SLO announcements reveal information about the prevailing market conditions, but also that they are the most important factor determining the 24-hour change in borrowing cost after the scheduled time of the operation.

Panel B of Table 12 shows that unexpected SLO announcements marginally increased the volume of bond lending in the following 24 hours; this effect is entirely driven by post-benchmark bonds. The average borrowing volume of non-benchmark securities rose by Can $\$ 40.3$ million in the 24 hours after an SLO that was expected with less than $33 \%$ probability. This is consistent with a public signal of higher-than-anticipated net demand for the security attracting additional supply, especially in securities owned by the less-active market participants.

The analysis of the information content of the volume of SLOs, presented in Table 13 , reinforces the conclusions of the analysis presented thus far. First, we see that higher BoC supply reduces borrowing fees: By between 30.2 bps (for post-benchmarks) and 56.6 bps (for $2 \mathrm{Y}$ bonds), with an average impact of 37.9 bps per Can $\$ 1$ billion of the bond injected in the SLO. Second, the surprise in the volume of the operation significantly affects all bond types. A Can $\$ 1$ billion higher-than-anticipated (lower-than-anticipated) loan by the BoC increases (decreases) its lending cost by 53.6 bps on average in the 24 hours after the SLO, 
consistent with the market learning that the true demand was higher (lower) than expected. This effect is higher for non-benchmarks than benchmark bonds - 59.8 bps vs 46.2 bps per Can $\$ 1$ billion of surprise in BoC lending - but decreases with bond maturity, from 67.5 bps for $2 \mathrm{Y}$ securities to 47.6 bps for $10 \mathrm{Y}$ bonds. Finally, in Panel B, we see that a surprisingly large SLO increases the lending volume of securities that are likely held by longer-horizon investors. In particular, every Can $\$ 1$ of $\mathrm{BoC}$ loans that is unanticipated increases the volume of lending in the $10 \mathrm{Y}$ bond by Can $\$ 0.36$ after the SLO.

This analysis of the value of SLO announcements not only serves to confirm the robustness of our empirical strategy, but also highlights the generality of our main message: communication of their operations helps central banks achieve their (monetary policy and financial stability) objectives. While neither necessary nor sufficient for this purpose, communication of concrete actions - in contrast with policy-related communication such as speeches,

reports and interest-rate decisions - of central banks speeds up market participants' ability to learn about the conditions in the market for borrowing cash and government securities. The resulting prices are more informative and are therefore more valuable inputs to the decision-making process of all agents in the economy.

\section{Conclusion}

This paper shows that announcement of their operations is costly for central banks because it moderates the desired effect of the changes in supply affected by the intervention. Nevertheless, major central banks choose to make public their loans to the financial system. Our analysis suggests that this is because central banks are the lenders of last resort in OTC markets; therefore, their public announcements provide valuable signals about the underlying demand and supply conditions in the markets in which they intervene. Central banks value the improved informativeness of overnight borrowing rates due to their announcements because it helps agents make better economic decisions. The existence of the trade-off be- 
tween the price impact per unit loaned out and the value of better price signals suggests the need for further research into the design of the content and timing of communication of operations to enhance central banks' effectiveness in achieving their policy mandates. 


\section{References}

Acharya, Sankarshan. 1988. "A Generalized Econometric Model and Tests of a Signalling Hypothesis With Two Discrete Signals." Journal of Finance 43 (2): 413-429.

Afonso, Gara and Ricardo Lagos. 2015. "Trade Dynamics in the Market for Federal Funds." Econometrica 83 (1): 263-313.

Aggarwal, Reena, Jennie Bai, and Luc Laeven. 2020. "Safe Asset Shortages: Evidence from the European Government Bond Lending Market." Journal of Financial and Quantitative Analysis. Forthcoming.

Amihud, Yakov and Kefei Li. 2006. "The Declining Information Content of Dividend Announcements and the Effects of Institutional Holdings." Journal of Financial and Quantitative Analysis 41 (3): 637-660.

Baklanova, Viktoria, Cecilia Caglio, Marco Cipriani, and Adam Copeland. 2019. "The Use of Collateral in Bilateral Repurchase and Securities Lending Agreements." Review of Economic Dynamics 33: 228-249.

Bartolini, Leonardo, Giuseppe Bertola, and Alessandro Prati. 2002. "Day-to-Day Monetary Policy and the Volatility of the Federal Funds Interest Rate." Journal of Money, Credit and Banking 34 (1): 137-159.

Benston, George, Paul Irvine, Jim Rosenfeld, and Joseph F. Sinkey Jr. 2003. "Bank Capital Structure, Regulatory Capital, and Securities Innovations." Journal of Money, Credit and Banking 35 (3): 301-322.

Berger, Helge, Michael Ehrmann, and Marcel Fratzscher. 2011. "Monetary Policy in the Media." Journal of Money, Credit and Banking 43 (4): 689-709.

Berger-Soucy, Léanne, Corey Garriott, and André Usche. 2018. "Government of Canada Fixed-Income Market Ecology.” Bank of Canada Staff Discussion Paper No. 2018-10.

Blinder, Alan S., Michael Ehrmann, Marcel Fratzscher, Jakob De Haan, and David-Jan Jansen. 2008. "Central Bank Communication and Monetary Policy: A Survey of Theory and Evidence." Journal of Economic Literature 46 (4): 910-45.

Boissel, Charles, François Derrien, Evren Ors, and David Thesmar. 2017. "Systemic Risk in Clearing Houses: Evidence from the European Repo Market." Journal of Financial Economics 125 (3): 511-536. 
Bulusu, Narayan and Pierre Guérin. 2019. "What Drives Interbank Loans? Evidence from Canada." Journal of Banking $\&$ Finance 106: 427-444.

Bulusu, Narayan and Sermin Gungor. 2020. "The Life-Cycle of Trading Activity and Liquidity of Government of Canada Bonds: Evidence from Cash, Repo and Securities Lending Markets." Canadian Journal of Economics. Forthcoming.

Carpenter, Seth and Selva Demiralp. 2006. "The Liquidity Effect in the Federal Funds Market: Evidence from Daily Open Market Operations." Journal of Money, Credit and Banking 38 (4): 901-920.

Chang, Bo Young and Bruno Feunou. 2013. "Measuring Uncertainty in Monetary Policy Using Implied Volatility and Realized Volatility." Bank of Canada Staff Working Paper No. 2013-37.

Cieslak, Anna and Andreas Schrimpf. 2019. "Non-Monetary News in Central Bank Communication." Journal of International Economics 118: 293-315.

Corradin, Stefano and Angela Maddaloni. 2020. "The Importance of Being Special: Repo Markets During the Crisis." Journal of Financial Economics. Forthcoming.

D’Amico, Stefania, Roger Fan, and Yuriy Kitsul. 2018. "The Scarcity Value of Treasury Collateral: Repo-Market Effects of Security-Specific Supply and Demand Factors." Journal of Financial and Quantitative Analysis 53 (5): 2103-2129.

D’Amico, Stefania and Mira Farka. 2011. "The Fed and the Stock Market: An Identification Based on Intraday Futures Data." Journal of Business 85 Economic Statistics 29 (1): $126-137$.

Demiralp, Selva and Dennis Farley. 2005. "Declining Required Reserves, Funds Rate Volatility, and Open Market Operations." Journal of Banking $\&$ Finance 29 (5): 1131-1152.

Duffie, Darrell. 1996. "Special Repo Rates." Journal of Finance 51 (2): 493-526.

Duffie, Darrell, Gaston Giroux, and Gustavo Manso. 2010. "Information Percolation." American Economic Journal: Microeconomics 2 (1): 100-111.

Duffie, Darrell, Semyon Malamud, and Gustavo Manso. 2009. "Information Percolation with Equilibrium Search Dynamics." Econometrica 77 (5): 1513-1574. 
Dufour, Alfonso, Miriam Marra, and Ivan Sangiorgi. 2019. "Determinants of Intraday Dynamics and Collateral Selection in Centrally Cleared and Bilateral Repos." Journal of Banking \&3 Finance 107: 105610.

Ehrmann, Michael and Jonathan Talmi. 2020. "Starting from a Blank Page? Semantic Similarity in Central Bank Communication and Market Volatility." Journal of Monetary Economics 111: 48-62.

Fleming, Michael J. and Kenneth D. Garbade. 2007. "Dealer Behavior in the Specials Market for US Treasury Securities." Journal of Financial Intermediation 16 (2): 204-228.

Fontaine, Jean-Sébastien, Corey Garriott, and Kyle Gray. 2016. "Securities Financing and Bond Market Liquidity." Bank of Canada Financial System Review June: 39-45.

Fontaine, Jean-Sébastien and Guillaume Nolin. 2019. "Measuring Limits of Arbitrage in Fixed-Income Markets." Journal of Financial Research 43 (3): 525-552.

Gao, Jeffrey, Francisco Rivadeneyra, and Gabriel Rodriguez. 2018. "The Government of Canada Debt Securities Data Set." Bank of Canada Technical Report No. 112.

Gorton, Gary and Andrew Metrick. 2012. "Securitized Banking and the Run on Repo." Journal of Financial Economics 104 (3): 425-451.

Graveline, Jeremy J. and Matthew R. McBrady. 2011. "Who Makes On-the-Run Treasuries Special?" Journal of Financial Intermediation 20 (4): 620-632.

Greenwood, Robin and Dimitri Vayanos. 2010. "Price Pressure in the Government Bond Market." American Economic Review 100 (2): 585-90.

Gürkaynak, Refet S., Brian Sack, and Eric T. Swanson. 2005. "Do Actions Speak Louder Than Words? The Response of Asset Prices to Monetary Policy Actions and Statements." International Journal of Central Banking 1 (1): 55-93.

Gürkaynak, Refet S. and Jonathan H. Wright. 2013. "Identification and Inference Using Event Studies." The Manchester School 81: 48-65.

Hamilton, James D. 1997. "Measuring the Liquidity Effect." American Economic Review 87 (1): 80-97.

Hansen, Stephen and Michael McMahon. 2016. "Shocking Language: Understanding the Macroeconomic Effects of Central Bank Communication." Journal of International Economics 99: S114-S133. 
Hansen, Stephen, Michael McMahon, and Matthew Tong. 2019. "The Long-Run Information Effect of Central Bank Communication." Journal of Monetary Economics 108: 185-202.

Harvey, Campbell R. and Roger D. Huang. 2002. "The Impact of the Federal Reserve Bank's Open Market Operations." Journal of Financial Markets 5 (2): 223-257.

Heckman, James J. 1979. "Sample Selection Bias as a Specification Error." Econometrica 47 (1): 153-161.

Hendershott, Terrence and Ananth Madhavan. 2015. "Click or Call? Auction Versus Search in the Over-the-Counter Market." Journal of Finance 70 (1): 419-447.

Hubert, Paul. 2015. "Do Central Bank Forecasts Influence Private Agents? Forecasting Performance Versus Signals." Journal of Money, Credit and Banking 47 (4): 771-789.

Iwatsubo, Kentaro and Satoshi Kawanishi. 2014. "The Information Improving Channel of Exchange Rate Intervention: How Do Official Announcements Work?" Journal of Financial Studies 22 (2): 27.

Jarociński, Marek and Peter Karadi. 2020. "Deconstructing Monetary Policy Surprises: The Role of Information Shocks." American Economic Journal: Macroeconomics 12 (2): 1-43.

Ji, Philip Inyeob. 2012. "Time-Varying Financial Stress Linkages: Evidence from the LIBOR-OIS Spreads." Journal of International Financial Markets, Institutions and Money 22 (4): 647-657.

Kopchak, Seth J. 2011. "The Liquidity Effect for Open Market Operations." Journal of Banking E Finance 35 (12): 3292-3299.

Krishnamurthy, Arvind, Stefan Nagel, and Dmitry Orlov. 2014. "Sizing Up Repo." Journal of Finance 69 (6): 2381-2417.

Kuttner, Kenneth N. 2001. "Monetary Policy Surprises and Interest Rates: Evidence from the Fed Funds Futures Market." Journal of Monetary Economics 47 (3): 523-544.

Mancini, Loriano, Angelo Ranaldo, and Jan Wrampelmeyer. 2016. "The Euro Interbank Repo Market." Review of Financial Studies 29 (7): 1747-1779.

Nayak, Subhankar and Nagpurnanand R. Prabhala. 2001. "Disentangling the Dividend Information in Splits: A Decomposition Using Conditional Event-Study Methods." Review of Financial Studies 14 (4): 1083-1116. 
Pasquariello, Paolo, Jennifer Roush, and Clara Vega. 2020. "Government Intervention and Strategic Trading in the US Treasury Market." Journal of Financial and Quantitative Analysis 55 (1): 117-157.

Popper, Helen and John D. Montgomery. 2001. "Information Sharing and Central Bank Intervention in the Foreign Exchange Market." Journal of International Economics 55 (2): 295-316.

Prabhala, Nagpurnanand R. 1997. "Conditional Methods in Event Studies and an Equilibrium Justification for Standard Event-Study Procedures." Review of Financial Studies 10 (1): 1-38.

Rempel, Mark. 2016. "Improving Overnight Loan Identification in Payments Systems." Journal of Money, Credit and Banking 48 (2-3): 549-564.

Rigobon, Roberto and Brian Sack. 2004. "The Impact of Monetary Policy on Asset Prices." Journal of Monetary Economics 51 (8): 1553-1575.

Rocheteau, Guillaume, Randall Wright, and Sylvia Xiaolin Xiao. 2018. "Open Market Operations." Journal of Monetary Economics 98: 114-128.

Rydqvist, Kristian and Mark Wu. 2016. "Pre-Auction Inventory and Bidding Behavior: Evidence from Canadian Treasury Auctions." Journal of Financial Markets 30: 78-102.

Schreft, Stacey L. and Bruce D. Smith. 1998. "The Effects of Open Market Operations in a Model of Intermediation and Growth." Review of Economic Studies 65 (3): 519-550.

Vayanos, Dimitri and Pierre-Olivier Weill. 2008. "A Search-Based Theory of the On-the-Run Phenomenon." Journal of Finance 63 (3): 1361-1398. 


\begin{tabular}{|c|c|}
\hline Variable & Description and source \\
\hline GoCRepoSpr & $\begin{array}{l}\text { Spread of volume-weighted rate of repos collateralised by Government of Canada securities over the Bank of } \\
\text { Canada overnight target rate in the } 24 \text { hours before the scheduled time of overnight OMO. Source: Bulusu } \\
\text { and Gungor (2020) }\end{array}$ \\
\hline GoCRepoVol & $\begin{array}{l}\text { Par value of Government of Canada securities used to collateralise repos in the } 24 \text { hours before the scheduled } \\
\text { time of overnight OMO. Source: Bulusu and Gungor }(2020)\end{array}$ \\
\hline CmbRepoSpr & $\begin{array}{l}\text { Spread of volume-weighted rate of repos collateralised by Canadian Mortgage Housing Corporation securities } \\
\text { over the Bank of Canada overnight target rate in the } 24 \text { hours before the scheduled time of overnight OMO. } \\
\text { Source: Bulusu and Gungor (2020) }\end{array}$ \\
\hline CmbRepoVol & $\begin{array}{l}\text { Par value of Canadian Mortgage Housing Corporation securities used to collateralise repos in the } 24 \text { hours } \\
\text { before the scheduled time of overnight OMO. Source: Bulusu and Gungor }(2020)\end{array}$ \\
\hline PrvRepoSpr & $\begin{array}{l}\text { Spread of volume-weighted rate of repos collateralised by Canadian provincial government securities over the } \\
\text { Bank of Canada overnight target rate in the } 24 \text { hours before the scheduled time of overnight OMO. Source: } \\
\text { Bulusu and Gungor }(2020)\end{array}$ \\
\hline PrvRepoVol & $\begin{array}{l}\text { Par value of Canadian provincial government securities used to collateralise repos in the } 24 \text { hours before the } \\
\text { scheduled time of overnight OMO. Source: Bulusu and Gungor (2020) }\end{array}$ \\
\hline OMOVol & Amount loaned in OMO by the Bank of Canada on day. Source: Bank of Canada \\
\hline OverdraftLVTS & $\begin{array}{l}\text { Value of loans provided by Bank of Canada to participants with negative balances in Canada's large value } \\
\text { payments system at the end of the day. Source: Bank of Canada }\end{array}$ \\
\hline RGAllot & $\begin{array}{l}\text { Volume of cash allotted in Government of Canada a.m. Receiver General auction conducted in day. Source: } \\
\text { Bank of Canada }\end{array}$ \\
\hline$R G S p r$ & $\begin{array}{l}\text { Spread of rate paid in Government of Canada a.m. Receiver General cash auction over the Bank of Canada } \\
\text { overnight target rate. Source: Bank of Canada }\end{array}$ \\
\hline GcRepoVol ${ }^{0.5 h P r e O M O}$ & $\begin{array}{l}\text { Volume of General Collateral repos backed by Government of Canada securities traded in the half an hour } \\
\text { before the scheduled time of the overnight OMO. Source: Bulusu and Gungor }(2020)\end{array}$ \\
\hline GcRepoSpr $0.5 h \operatorname{PreOMO}$ & $\begin{array}{l}\text { Difference between volume-weighted average rate of General Collateral repos backed by Government of } \\
\text { Canada securities traded in the } 30 \text { minutes before the scheduled time of the overnight OMO and the Bank } \\
\text { of Canada overnight target rate. Source: Bulusu and Gungor }(2020)\end{array}$ \\
\hline UnsecVol ${ }^{0.5 h P r e O M O}$ & $\begin{array}{l}\text { Volume of unsecured interbank loans traded in the } 30 \text { minutes before the scheduled time of the overnight } \\
\text { OMO. Source: Rempel (2016) }\end{array}$ \\
\hline UnsecSpr ${ }^{0.5 h P r e O M O}$ & $\begin{array}{l}\text { Difference between volume-weighted average rate of unsecured interbank loans traded in the } 30 \text { minutes } \\
\text { before the scheduled time of OMO and the Bank of Canada overnight target rate. Source: Rempel (2016) }\end{array}$ \\
\hline CumBalLVTS & $\begin{array}{l}\text { Cumulative balance (Can } \$ \text { ) held by participants in Canada's large value payments system at the end of the } \\
\text { day (6:30 p.m.). Source: Bank of Canada }\end{array}$ \\
\hline GoCSecPDInv & $\begin{array}{l}\text { Primary dealers' inventory (par value) of the Government of Canada security auctioned on day. Source: } \\
\text { Bank of Canada }\end{array}$ \\
\hline$V I X C$ & S\&P/TSX 60 VIX Index. Source: https://m-x.ca/indicesmx_vixc_en.php \\
\hline ONtgt & $\begin{array}{l}\text { Bank of Canada overnight target rate. Source: https://www.bankofcanada.ca/rates/interest- } \\
\text { rates/canadian-interest-rates/ }\end{array}$ \\
\hline$C O I S^{3 m}$ & $\begin{array}{l}\text { Difference between three-month Canadian Dollar Offer Rate and three-month Overnight Interest Rate Swap } \\
\text { spread. Source: Bank of Canada: https://credit.bankofcanada.ca/financialindicators }\end{array}$ \\
\hline ImpVolOptFut & $\begin{array}{l}\text { Implied volatility of options on three-month futures on the Canadian Dollar Offer Rate with } 30 \text { days to } \\
\text { expiry. Source: Chang and Feunou (2013) }\end{array}$ \\
\hline RelVal & Index of limits to arbitrage in the Government of Canada bond market. Source: Fontaine and Nolin (2019) \\
\hline
\end{tabular}

Table 1: Variable description-OMOs. This table contains the description and sources of variables used for estimating effect of central bank communication of open market operations. 


\begin{tabular}{|c|c|c|c|c|c|c|}
\hline & \multicolumn{2}{|c|}{ ON tgt rate $-0.50 \%$} & \multicolumn{2}{|c|}{ ON tgt rate $-0.75 \%$} & \multicolumn{2}{|c|}{ ON tgt rate $-1.00 \%$} \\
\hline OMOInd & 0 & 1 & 0 & 1 & 0 & 1 \\
\hline Num obs & 129 & 21 & 140 & 14 & 944 & 135 \\
\hline \multicolumn{7}{|c|}{ Panel A: Dependent variables } \\
\hline$\Delta G o C R e p o V o l_{t+1}(\$ \mathrm{Bn})$ & -0.13 & 0.92 & -0.27 & 2.59 & -0.18 & 0.87 \\
\hline$\Delta G o C R e p o S p r_{t+1}(\mathrm{bps})$ & -0.01 & 0.57 & 0.03 & -0.80 & 0.03 & -0.05 \\
\hline$\Delta C m b R e p o V o l_{t+1}(\$ \mathrm{Bn})$ & -0.06 & 0.25 & -0.02 & 0.28 & -0.06 & 0.33 \\
\hline$\Delta C m b R e p o S p r_{t+1}(\mathrm{bps})$ & 0.02 & 0.00 & -0.12 & -0.38 & 0.00 & 0.13 \\
\hline$\Delta$ PrvRepoVol $l_{t+1}(\$ \mathrm{Bn})$ & -0.04 & 0.23 & -0.01 & 0.07 & -0.01 & 0.12 \\
\hline$\Delta \operatorname{PrvRepoSpr}_{t+1}$ (bps) & 0.11 & -0.32 & -0.15 & -0.26 & 0.04 & -0.13 \\
\hline \multicolumn{7}{|c|}{ Panel B: Predictors of OMOs } \\
\hline OverdraftLVT $S_{t-1}(\$ \mathrm{Bn})$ & 0.02 & 0.00 & 0.01 & 0.04 & 0.03 & 0.01 \\
\hline CumBalLVT $S_{t-1}(\$ \mathrm{Bn})$ & 0.22 & 0.54 & 0.14 & 0.18 & 0.08 & 0.22 \\
\hline GoCRepoVol $l_{t}^{0.5 h P r e O M O}(\$ \mathrm{Bn})$ & 0.14 & 0.07 & 0.08 & 0.17 & 0.11 & 0.13 \\
\hline GoCRepoSpr $r_{t}^{0.5 h P r e O M O}$ (bps) & 0.39 & 4.24 & -0.12 & 3.30 & -0.52 & 0.91 \\
\hline UnsecVol ${ }_{t}^{0.5 h P r e O M O}(\$ \mathrm{MM})$ & 0.39 & 0.43 & 0.36 & 0.47 & 0.41 & 0.38 \\
\hline UnsecSpro ${ }_{t}^{0.5 h P r e O M O}$ (bps) & -10.84 & -15.74 & -10.95 & -8.93 & -6.84 & -7.84 \\
\hline $\operatorname{RGAllot}_{t}(\$ \mathrm{Bn})$ & 3.72 & 3.48 & 4.11 & 3.61 & 3.54 & 3.94 \\
\hline$R G S p r_{t}(\mathrm{bps})$ & -1.99 & 5.26 & -2.90 & 2.55 & -1.94 & 0.15 \\
\hline $\operatorname{GoCSecPDInv}_{t}(\$ \mathrm{Bn})$ & 1.36 & 1.59 & 1.55 & 1.01 & 1.71 & 1.38 \\
\hline$V I X C_{t}$ & 19.78 & 18.88 & 16.19 & 16.30 & 16.48 & 16.83 \\
\hline$C O I S_{t}^{3 m}(\mathrm{bps})$ & 27.48 & 33.07 & 27.05 & 28.88 & 27.25 & 27.24 \\
\hline \multicolumn{7}{|c|}{ Panel C: OMO communication effect-controls } \\
\hline $\mathrm{OMOVOl}_{t}(\$ \mathrm{Bn})$ & 0.00 & 1.14 & 0.00 & 0.69 & 0.00 & 0.63 \\
\hline$\Delta C O I S_{t+1}^{3 m}(\mathrm{bps})$ & 0.04 & 0.36 & 0.01 & -0.66 & 0.03 & -0.11 \\
\hline$\Delta$ ImpVolOptFut $t_{t+1}$ & 0.04 & 0.08 & -0.04 & -0.21 & -0.05 & 0.36 \\
\hline$\Delta V I X C_{t+1}$ & 0.01 & 0.09 & -0.04 & -0.09 & 0.01 & -0.03 \\
\hline$\Delta \operatorname{RelVal}_{t+1}$ & 0.01 & -0.02 & 0.01 & 0.04 & 0.00 & 0.00 \\
\hline
\end{tabular}

Table 2: Summary statistics-OMOs. This table presents the sample average of the variables in the first column for sub-samples indicated by the top two rows. OMOInd takes value 1 on days when the Bank of Canada injected liquidity using OMOs and zero on the rest. $\Delta X_{t+1}$ is the change in the variable $X$ in the 24 hours after the scheduled time on day $t$ of the OMO (compared with the 24 hours before it). The subscript $t-1(t)$ for all other variables is used to highlight that they are measured on the day before (on the day of) the scheduled OMO. The sample spans the period from August 28, 2009, to December 31, 2015. 


\begin{tabular}{|c|c|}
\hline OMOInd $_{t-1}$ & $\begin{array}{c}0.83 \\
(3.50)\end{array}$ \\
\hline $\mathrm{OMOVol}_{t}\left(\times 10^{10}\right)$ & $\begin{array}{c}3.23 \\
(1.01)\end{array}$ \\
\hline OverdraftLVT $S_{t-1}\left(\times 10^{9}\right)$ & $\begin{array}{l}-1.70 \\
(-1.39)\end{array}$ \\
\hline CumBalLVTS $S_{t-1}\left(\times 10^{10}\right)$ & $\begin{array}{l}-3.63 \\
(-2.54)\end{array}$ \\
\hline GoCRepoVolt $l_{t}^{0.5 h P r e O M O}\left(\times 10^{10}\right)$ & $\begin{array}{c}4.62 \\
(1.26)\end{array}$ \\
\hline GoCRepoSpr ${ }_{t}^{0.5 h P r e O M O}$ & $\begin{array}{l}22.77 \\
(6.53)\end{array}$ \\
\hline UnsecVol ${ }_{t}^{0.5 h P r e O M O}\left(\times 10^{11}\right)$ & $\begin{array}{c}5.33 \\
(0.30)\end{array}$ \\
\hline UnsecSpr $_{t}^{0.5 h P r e O M O}$ & $\begin{array}{c}0.71 \\
(1.08)\end{array}$ \\
\hline$R_{\text {GAllot }}\left(\times 10^{11}\right)$ & $\begin{array}{l}8.49 \\
(2.04)\end{array}$ \\
\hline$R G S p r_{t}$ & $\begin{array}{l}19.46 \\
(6.17)\end{array}$ \\
\hline $\operatorname{GoCSecPDInv}_{t}\left(\times 10^{12}\right)$ & $\begin{array}{c}-9.74 \\
(-0.64)\end{array}$ \\
\hline$V I X C_{t}$ & $\begin{array}{c}0.00 \\
(0.21)\end{array}$ \\
\hline$C O I S_{t}^{3 m}$ & $\begin{array}{c}-2.38 \\
(-1.32)\end{array}$ \\
\hline $\mathrm{N}$ & 1478 \\
\hline Pseudo- $R^{2}(\%)$ & 35.23 \\
\hline
\end{tabular}

Table 3: Expectation of OMO announcement. This table presents the coefficients of the probit model for the expectation of Bank of Canada overnight OMOs, together with the Z-statistics reported in parentheses. OMOInd $_{t-1}$ takes the value 1 if the Bank of Canada conducted an OMO on the previous trading day and 0 otherwise. Table 1 describes the rest of the variables used for predicting the OMO. The data span the period from August 28, 2009, to December 31, 2015. 


\begin{tabular}{|c|c|c|c|}
\hline & GoC & $\mathrm{CMB}$ & PRV \\
\hline \multicolumn{4}{|c|}{ Panel A: 24-hour change in cash lending rate } \\
\hline OMO_Comm ${ }_{t}\left(\times 10^{3}\right)$ & $\begin{array}{c}3.47 \\
(2.66)\end{array}$ & $\begin{array}{c}6.16 \\
(2.37)\end{array}$ & $\begin{array}{c}2.64 \\
(0.88)\end{array}$ \\
\hline OMOVol $\left(\times 10^{12}\right)$ & $\begin{array}{l}-4.54 \\
(-1.85)\end{array}$ & $\begin{array}{l}-4.15 \\
(-0.81)\end{array}$ & $\begin{array}{l}-4.23 \\
(-1.22)\end{array}$ \\
\hline$\Delta O N t g t_{t+1}$ & $\begin{array}{l}-0.13 \\
(-1.34)\end{array}$ & $\begin{array}{l}-0.17 \\
(-1.07)\end{array}$ & $\begin{array}{l}-0.23 \\
(-1.07)\end{array}$ \\
\hline$\Delta C O I S_{t+1}^{3 m}$ & $\begin{array}{c}0.06 \\
(1.46)\end{array}$ & $\begin{array}{l}-0.02 \\
(-0.29)\end{array}$ & $\begin{array}{c}0.10 \\
(1.06)\end{array}$ \\
\hline$\Delta I m p V o l O p t F u t_{t+1}\left(\times 10^{4}\right)$ & $\begin{array}{c}0.92 \\
(1.34)\end{array}$ & $\begin{array}{c}0.31 \\
(0.71)\end{array}$ & $\begin{array}{c}1.88 \\
(1.51)\end{array}$ \\
\hline$\Delta V I X C_{t+1}\left(\times 10^{4}\right)$ & $\begin{array}{l}-1.34 \\
(-0.85)\end{array}$ & $\begin{array}{l}-0.82 \\
(-0.27)\end{array}$ & $\begin{array}{c}1.29 \\
(0.22)\end{array}$ \\
\hline$\Delta \operatorname{RelVal}_{t+1}\left(\times 10^{3}\right)$ & $\begin{array}{c}1.36 \\
(1.00)\end{array}$ & $\begin{array}{c}1.92 \\
(0.87)\end{array}$ & $\begin{array}{c}2.30 \\
(0.72)\end{array}$ \\
\hline $\mathrm{N}$ & 1475 & 1475 & 1466 \\
\hline $\operatorname{Adj} R^{2}(\%)$ & 6.21 & 5.57 & 2.61 \\
\hline \multicolumn{4}{|c|}{ Panel B: 24-hour change in cash lending volume } \\
\hline $\mathrm{OMO}_{\mathrm{C}} \mathrm{Comm}_{t}\left(\times 10^{-8}\right)$ & $\begin{array}{c}1.77 \\
(0.56)\end{array}$ & $\begin{array}{c}1.90 \\
(1.20)\end{array}$ & $\begin{array}{c}1.93 \\
(1.54)\end{array}$ \\
\hline $\mathrm{OMOVol}_{t}$ & $\begin{array}{c}1.57 \\
(2.38)\end{array}$ & $\begin{array}{c}0.18 \\
(0.57)\end{array}$ & $\begin{array}{l}-0.18 \\
(-0.87)\end{array}$ \\
\hline$\Delta O N \operatorname{Ngt}_{t+1}\left(\times 10^{-9}\right)$ & $\begin{array}{l}-1.91 \\
(-0.24)\end{array}$ & $\begin{array}{c}8.90 \\
(1.37)\end{array}$ & $\begin{array}{c}3.91 \\
(2.16)\end{array}$ \\
\hline$\Delta C O I S_{t+1}^{3 m}\left(\times 10^{-9}\right)$ & $\begin{array}{l}-4.39 \\
(-0.38)\end{array}$ & $\begin{array}{l}-0.14 \\
(-0.03)\end{array}$ & $\begin{array}{c}4.66 \\
(1.93)\end{array}$ \\
\hline$\Delta I m p V o l O p t F u t_{t+1}\left(\times 10^{-7}\right)$ & $\begin{array}{l}-3.59 \\
(-1.76)\end{array}$ & $\begin{array}{c}0.89 \\
(1.01)\end{array}$ & $\begin{array}{l}-0.16 \\
(-0.22)\end{array}$ \\
\hline$\Delta V I X C_{t+1}\left(\times 10^{-7}\right)$ & $\begin{array}{l}-5.68 \\
(-0.92)\end{array}$ & $\begin{array}{l}-0.35 \\
(-0.09)\end{array}$ & $\begin{array}{l}-2.97 \\
(-1.45)\end{array}$ \\
\hline$\Delta \operatorname{RelVal}_{t+1}\left(\times 10^{-8}\right)$ & $\begin{array}{l}-1.19 \\
(-0.23)\end{array}$ & $\begin{array}{c}2.77 \\
(1.11)\end{array}$ & $\begin{array}{l}-0.06 \\
(-0.04)\end{array}$ \\
\hline $\mathrm{N}$ & 1475 & 1475 & 1475 \\
\hline $\operatorname{Adj} R^{2}(\%)$ & 1.59 & 0.76 & 0.82 \\
\hline
\end{tabular}

Table 4: Communication effect of OMO announcement. This table presents the estimates of the coefficients of the regression $\Delta y=\alpha+\pi O M O \_C o m m+\beta^{\prime} Z+\epsilon$ along with the heteroskedasticity-consistent T-statistics in parentheses. In Panel A (B), $\Delta y$ is the 24-hour change in the overnight loan rate over the Bank of Canada target rate (overnight loan volume) after the scheduled time of the OMO. OMO_Comm is the estimated surprise due to the communication of the OMO, and $Z$ is a vector of controls. Each column contains the results for the sample of overnight loans backed by the collateral class indicated in the first row: 'GoC', 'CMB' and 'PRV' represent, respectively, fixed-income securities issued by the Government of Canada, the Canadian Housing Mortgage Corporation, and provincial governments of Canada. The sample spans the period from August 28, 2009, to December 31, 2015. 


\begin{tabular}{|c|c|}
\hline OMOInd $_{t-1}$ & $\begin{array}{c}0.59 \\
(3.31)\end{array}$ \\
\hline$O M O V o l_{t-1}$ & $\begin{array}{c}0.37 \\
(1.67)\end{array}$ \\
\hline Overdraft $L V T S_{t-1}$ & $\begin{array}{l}-1.18 \\
(-1.28)\end{array}$ \\
\hline CumBalLVT $S_{t-1}$ & $\begin{array}{c}-0.33 \\
(-2.83)\end{array}$ \\
\hline GoCRepoVol ${ }_{t}^{0.5 h P r e O M O}$ & $\begin{array}{c}0.33 \\
(1.10)\end{array}$ \\
\hline GoCRepoSpr $r_{t}^{0.5 h P r e O M O}$ & $\begin{array}{l}17.99 \\
(6.53)\end{array}$ \\
\hline UnsecVolt ${ }_{t}^{0.5 h P r e O M O}$ & $\begin{array}{c}0.17 \\
(1.20)\end{array}$ \\
\hline UnsecSpr ${ }_{t}^{0.5 h P r e O M O}$ & $\begin{array}{c}0.61 \\
(1.16)\end{array}$ \\
\hline RGAllot $_{t}$ & $\begin{array}{c}0.07 \\
(2.23)\end{array}$ \\
\hline$R G S p r_{t}$ & $\begin{array}{l}15.11 \\
(6.12)\end{array}$ \\
\hline GoCSecPDInv $_{t}$ & $\begin{array}{c}-0.01 \\
(-0.51)\end{array}$ \\
\hline$V I X C_{t}$ & $\begin{array}{c}0.01 \\
(0.60)\end{array}$ \\
\hline$C O I S_{t}^{3 m}$ & $\begin{array}{c}-1.69 \\
(-1.20) \\
\end{array}$ \\
\hline $\mathrm{N}$ & 1478 \\
\hline Pseudo- $R^{2}(\%)$ & 30.84 \\
\hline
\end{tabular}

Table 5: Expectation of OMO volume. This table presents the coefficients of the Tobit model — with lower and upper bounds at 0 and 1.5 billion, respectively - for the volume of lending by the Bank of Canada in overnight OMOs, together with the Z-statistics reported in parentheses. Table1 1 in the main text describes the variables used for predicting the OMO loan volume. The data span the period from August 28, 2009, to December 31, 2015. 


\begin{tabular}{|c|c|c|c|}
\hline & GoC & $\mathrm{CMB}$ & PRV \\
\hline \multicolumn{4}{|c|}{ Panel A: 24-hour change in cash lending rate } \\
\hline $\mathrm{OMOVOl}_{-} \mathrm{Comm}_{t}\left(\times 10^{12}\right)$ & $\begin{array}{c}1.83 \\
(4.01)\end{array}$ & $\begin{array}{c}2.78 \\
(2.42)\end{array}$ & $\begin{array}{c}1.08 \\
(1.08)\end{array}$ \\
\hline $\mathrm{OMOVol}_{t}\left(\times 10^{12}\right)$ & $\begin{array}{c}0.64 \\
(0.36)\end{array}$ & $\begin{array}{c}4.80 \\
(1.20)\end{array}$ & $\begin{array}{l}-0.44 \\
(-0.18)\end{array}$ \\
\hline$\Delta O N \operatorname{sgt}_{t+1}$ & $\begin{array}{l}-0.12 \\
(-1.28)\end{array}$ & $\begin{array}{c}-0.17 \\
(-1.01)\end{array}$ & $\begin{array}{l}-0.23 \\
(-1.06)\end{array}$ \\
\hline$\Delta C O I S_{t+1}^{3 m}$ & $\begin{array}{c}0.05 \\
(1.36)\end{array}$ & $\begin{array}{l}-0.03 \\
(-0.41)\end{array}$ & $\begin{array}{c}0.10 \\
(1.02)\end{array}$ \\
\hline$\Delta I m p V o l O p t F u t_{t+1}\left(\times 10^{4}\right)$ & $\begin{array}{c}0.97 \\
(1.43)\end{array}$ & $\begin{array}{c}0.42 \\
(0.98)\end{array}$ & $\begin{array}{l}1.91 \\
(1.54)\end{array}$ \\
\hline$\Delta V I X C_{t+1}\left(\times 10^{4}\right)$ & $\begin{array}{l}-1.26 \\
(-0.80)\end{array}$ & $\begin{array}{l}-0.54 \\
(-0.17)\end{array}$ & $\begin{array}{l}1.50 \\
(0.25)\end{array}$ \\
\hline$\Delta \operatorname{RelVal}_{t+1}\left(\times 10^{3}\right)$ & $\begin{array}{c}1.38 \\
(1.01)\end{array}$ & $\begin{array}{c}2.02 \\
(0.90)\end{array}$ & $\begin{array}{c}2.24 \\
(0.70)\end{array}$ \\
\hline $\mathrm{N}$ & 1475 & 1475 & 1466 \\
\hline $\operatorname{Adj} R^{2}(\%)$ & 6.48 & 5.14 & 2.55 \\
\hline \multicolumn{4}{|c|}{ Panel B: 24-hour change in cash lending volume } \\
\hline OMOVol_Comm $m_{t}$ & $\begin{array}{c}-0.06 \\
(-0.48)\end{array}$ & $\begin{array}{c}0.04 \\
(0.53)\end{array}$ & $\begin{array}{c}0.04 \\
(0.95)\end{array}$ \\
\hline$O M O V o l_{t}$ & $\begin{array}{l}1.76 \\
(3.61)\end{array}$ & $\begin{array}{c}0.43 \\
(1.75)\end{array}$ & $\begin{array}{c}0.07 \\
(0.50)\end{array}$ \\
\hline$\Delta O N \operatorname{Ngt}_{t+1}\left(\times 10^{-9}\right)$ & $\begin{array}{l}-2.07 \\
(-0.26)\end{array}$ & $\begin{array}{c}8.97 \\
(1.38)\end{array}$ & $\begin{array}{c}4.02 \\
(2.24)\end{array}$ \\
\hline$\Delta C O I S_{t+1}^{3 m}\left(\times 10^{-9}\right)$ & $\begin{array}{l}-5.45 \\
(-0.47)\end{array}$ & $\begin{array}{l}-0.66 \\
(-0.13)\end{array}$ & $\begin{array}{c}4.22 \\
(1.77)\end{array}$ \\
\hline$\Delta I m p V o l O p t F u t_{t+1}\left(\times 10^{-7}\right)$ & $\begin{array}{l}-3.42 \\
(-1.72)\end{array}$ & $\begin{array}{c}0.85 \\
(0.96)\end{array}$ & $\begin{array}{l}-0.17 \\
(-0.22)\end{array}$ \\
\hline$\Delta V I X C_{t+1}\left(\times 10^{-7}\right)$ & $\begin{array}{l}-5.68 \\
(-0.91)\end{array}$ & $\begin{array}{l}-0.83 \\
(-0.22)\end{array}$ & $\begin{array}{l}-2.95 \\
(-1.45)\end{array}$ \\
\hline$\Delta \operatorname{RelVal}_{t+1}\left(\times 10^{-8}\right)$ & $\begin{array}{c}-1.49 \\
(-0.29) \\
\end{array}$ & $\begin{array}{c}2.64 \\
(1.06) \\
\end{array}$ & $\begin{array}{c}-0.02 \\
(-0.01) \\
\end{array}$ \\
\hline $\mathrm{N}$ & 1475 & 1475 & 1475 \\
\hline $\operatorname{Adj} R^{2}(\%)$ & 1.56 & 0.66 & 0.53 \\
\hline
\end{tabular}

Table 6: Communication effect of OMO volume announcement. This table presents the estimates of the coefficients of the regression $\Delta y=\alpha_{v}+\pi_{v} O M O V o l_{-} C_{o m m}+\beta_{v}^{\prime} Z+\epsilon_{v}$ along with the heteroskedasticityconsistent T-statistics in parentheses. In Panel A (B), $\Delta y$ is the 24-hour change in the overnight loan rate over the Bank of Canada target rate (overnight loan volume) after the scheduled time of the OMO. OMOVol_Comm is the surprise in OMO volume measured as the difference between the realised and expected OMO volume, and $Z$ is a vector of controls. Each column contains the results for the sample of overnight loans backed by the collateral class indicated in the first row: 'GoC', 'CMB' and 'PRV' represent, respectively, fixed-income securities issued by the Government of Canada, the Canadian Housing Mortgage Corporation, and provincial governments of Canada. The sample spans the period from August 28, 2009, to December 31, 2015. 


\begin{tabular}{|c|c|}
\hline Variable & Description and source \\
\hline BorrowFee & $\begin{array}{l}\text { Difference between the Bank of Canada overnight target rate and the volume-weighted average rate of repos collateralised } \\
\text { by the security traded in the } 24 \text { hours before the scheduled time of the Bank of Canada SLO. Source: Bulusu and Gungor } \\
(2020)\end{array}$ \\
\hline BorrowVol & $\begin{array}{l}\text { Par value of security used to collateralise repos traded } 24 \text { hours before the scheduled time of the Bank of Canada SLO. } \\
\text { Source: Bulusu and Gungor (2020) }\end{array}$ \\
\hline BorrowVol PreSLO & $\begin{array}{l}\text { Par value of the security used to collateralise repos on the day before the scheduled time of the Bank of Canada SLO. } \\
\text { Source: See description of the variable BorrowVol }\end{array}$ \\
\hline BorrowFee PreSLO $^{\text {P }}$ & $\begin{array}{l}\text { Spread between the Bank of Canada overnight target rate and the volume-weighted average rate of all repos collateralised } \\
\text { by security on the day before the scheduled time of the Bank of Canada SLO. Source: See description of the variable } \\
\text { BorrowVol }\end{array}$ \\
\hline NetOutstand & $\begin{array}{l}\text { Par value of outstanding less par value of stripping in security. Source: Data on oustanding amounts in each security is } \\
\text { from Gao, Rivadeneyra, and Rodriguez (2018). Data on end-of-month net amount stripped in each security is provided } \\
\text { by the depository institution in charge of all stripping, reconstitution and packaging activity in GoC bonds in Canada is } \\
\text { provided by CDS Innovations. All days in a month are assumed to have the same net outstanding stripped as at the end } \\
\text { of the month }\end{array}$ \\
\hline FornInstHold & $\begin{array}{l}\text { Estimate of par value of security held by central banks and other official institutions on day. Source: Bank of Canada } \\
\text { estimates }\end{array}$ \\
\hline SecLendUtil & $\begin{array}{l}\text { Fraction of security made available to securities lending agents by security owners on loan. Source: Markit Securities } \\
\text { Finance }\end{array}$ \\
\hline TotSLOVol & Total par value of security loaned by Bank of Canada in SLOs up to date. Source: Bank of Canada \\
\hline TotSLONum & Total number of days the security was loaned out by the Bank of Canada up to date. Source: Bank of Canada \\
\hline PdInvPostAucTm & $\begin{array}{l}\text { Sum of inventory held by Primary Dealers who participated in the last (primary) auction for the GoC bond of the same } \\
\text { term as the instrument, post allotment. Source: Bank of Canada }\end{array}$ \\
\hline DaysPrevAucTm & Number of days since the last auction in the GoC bond of the same term as the instrument. Source: Bank of Canada \\
\hline SizeNextAucTm & Volume of securities auctioned in the nearest GoC bond auction after the current trading day. Source: Bank of Canada \\
\hline DaysNextAucTm & Days to the next GoC bond auction in security of same term (after the current trading day). Source: Bank of Canada \\
\hline IndDelivFut & $\begin{array}{l}\text { An indicator that takes the value of } 1 \text { if the instrument was the deliverable against any open futures contract on the day and } \\
0 \text { otherwise. Source: The list of deliverables for each open contract is published in news circulars issued by the Montréal } \\
\text { Stock Exchange. The open interest in futures contracts and the implied repo rate for the three cheapest to deliver bonds } \\
\text { for each futures contract is at the following website of the Montréal Exchange: https://www.m-x.ca/nego_fin_jour_en.php }\end{array}$ \\
\hline IndDelivMthFut & $\begin{array}{l}\text { An indicator that takes the value of } 1 \text { for an instrument if it is deliverable against a futures contract that is in its delivery } \\
\text { month, i.e., in the period when the bond can be delivered to settle the futures contract. Source: See description of variable } \\
\text { IndDelivFut }\end{array}$ \\
\hline $3 m O n t G o C Y l d S p r$ & $\begin{array}{l}\text { Spread between the yield of Ontario debt and GoC debt with three months to maturity. Source: Bank of Canada publishes } \\
\text { the GoC yield curve; the daily zero coupon yield curve of Ontario is obtained by fitting a Svensson model to bond prices } \\
\text { obtained from CDS Innovations }\end{array}$ \\
\hline $10 y O n t G o C Y l d S p r$ & $\begin{array}{l}\text { Spread between the yield of Ontario debt and GoC debt with ten years to maturity. Source: See the description of the } \\
\text { variable } 3 \text { mOntGoCYldSpr }\end{array}$ \\
\hline $3 m C p G o C Y l d S p r$ & $\begin{array}{l}\text { Spread between the yield of commercial paper and GoC debt with three months to maturity. Source: Bank of Canada } \\
\text { publishes the GoC yield curve; the yield of commercial paper with three months to maturity is obtained using trading data } \\
\text { from CDS Innovations }\end{array}$ \\
\hline Age & Age of security (in years). Source: Gao, Rivadeneyra, and Rodriguez $(2018)$ \\
\hline SLOVol & Par value of security allotted by the Bank of Canada in SLO on day. Source: Bank of Canada \\
\hline FutOI & $\begin{array}{l}\text { Total open interest in all active futures contracts for which the security is deliverable, as of the end of current trading day. } \\
\text { Source: See description of variable IndDelivFut }\end{array}$ \\
\hline FutOIDelivMth & $\begin{array}{l}\text { Total open interest in all active futures contracts in the delivery month for which the ISIN is deliverable, as of the end of } \\
\text { current trading day. Source: See description of variable IndDelivFut }\end{array}$ \\
\hline IndBch & $\begin{array}{l}\text { Indicator that takes the value of } 1 \text { if the bond is a benchmark on the current trading day, and } 0 \text { otherwise. Source: Gao, } \\
\text { Rivadeneyra, and Rodriguez (2018) }\end{array}$ \\
\hline
\end{tabular}

Table 7: Variable description-SLOs. This table contains the description and sources of variables used for estimating effect of central bank communication of securities lending operations. 


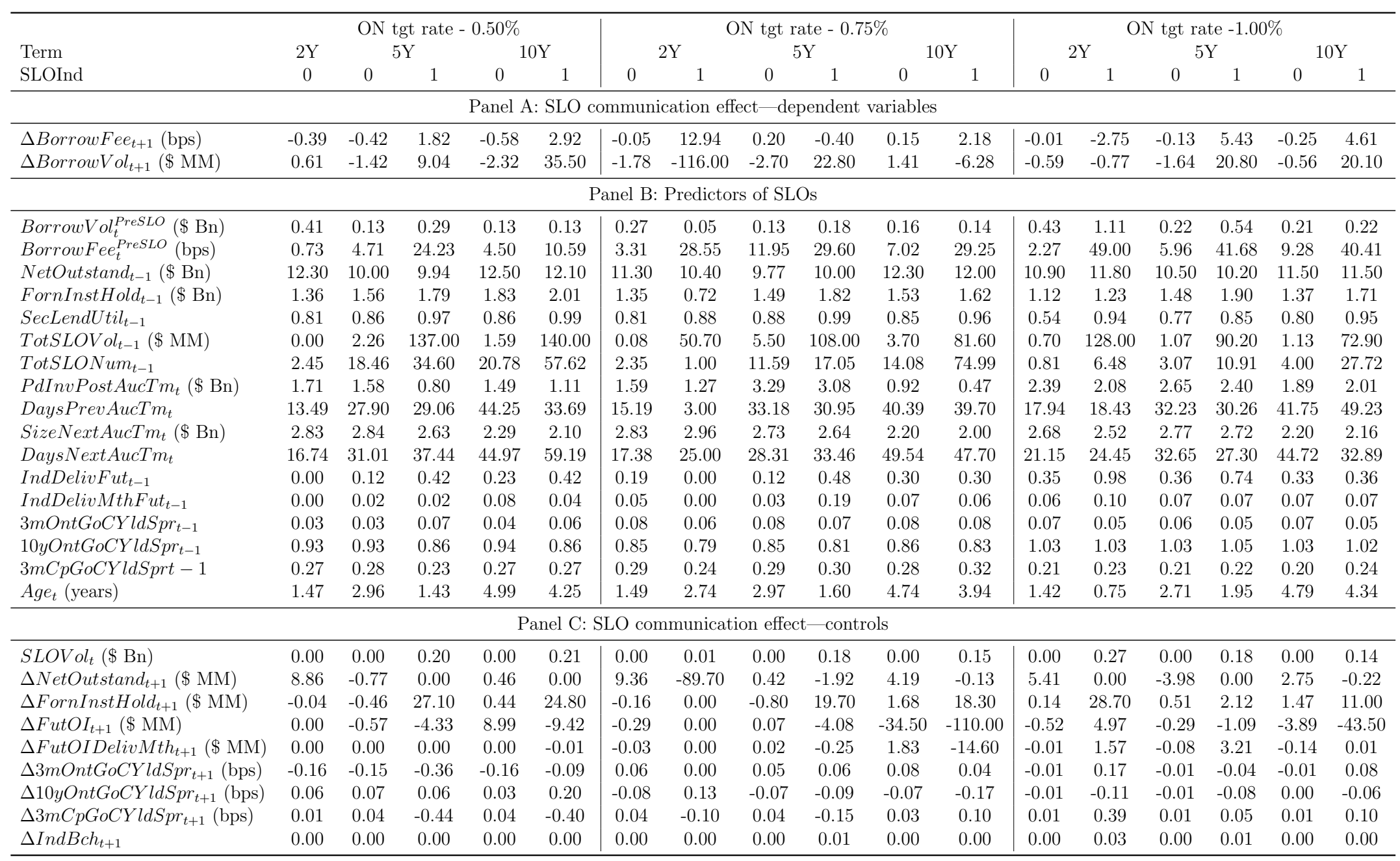

Table 8: Summary statistics — communication effect of announcement of Securities Lending Operations (SLOs). This table presents the sample average of the variables in the first column, for sub-samples indicated by the first three rows. We present the summary statistics separately for the three levels of the Bank of Canada overnight target rate in our sample, for bonds with two (2Y), five (5Y) and ten (10Y) years to maturity at issued $(10 \mathrm{Y})$ and for bonds that were $(S L O I n d=1)$ and were not loaned out $(S L O I n d=0)$ by the Bank of Canada in an overnight securities lending operation. $\Delta X_{t+1}$ is the change in the variable $X$ in the 24 hours after the scheduled time on day $t$ of the OMO (compared with the 24 hours before it). The subscript $t-1(t)$ for all other variables is used to highlight that they are measured on the day before (on the day of) the scheduled OMO. The sample spans the period from August 28, 2009, to December 31, 2015. 


\begin{tabular}{|c|c|c|c|c|c|c|c|c|c|c|}
\hline & \multirow{2}{*}{$\begin{array}{c}\text { Term } \\
\text { ON target }(\%)\end{array}$} & \multicolumn{3}{|c|}{$2 \mathrm{Y}$} & \multicolumn{3}{|c|}{$5 \mathrm{Y}$} & \multicolumn{3}{|c|}{$10 \mathrm{Y}$} \\
\hline & & 0.50 & 0.75 & 1.00 & 0.50 & 0.75 & 1.00 & 0.50 & 0.75 & 1.00 \\
\hline \multirow{3}{*}{ Pre-benchmark } & TotSLONum & & & 1 & & & & & & \\
\hline & TotSLOVol (\$ Bn) & & & 0.11 & & & & & & \\
\hline & TotSLOBids & & & 1 & & & & & & \\
\hline \multirow{3}{*}{ Benchmark } & TotSLONum & & & 19 & 3 & 23 & 37 & 6 & 6 & 66 \\
\hline & TotSLOVol $(\$ \mathrm{Bn})$ & & & 6.13 & 0.93 & 7.11 & 10.44 & 2.32 & 2.20 & 8.85 \\
\hline & TotSLOBids & & & 32 & 5 & 43 & 61 & 10 & 7 & 98 \\
\hline \multirow{3}{*}{ Post-benchmark } & TotSLONum & & 3 & 20 & 45 & 81 & 75 & 20 & 64 & 102 \\
\hline & TotSLOVol (\$ Bn) & & 0.25 & 4.74 & 8.84 & 11.83 & 9.93 & 3.20 & 8.51 & 14.23 \\
\hline & TotSLOBids & & 3 & 35 & 70 & 132 & 129 & 26 & 84 & 156 \\
\hline
\end{tabular}

Table 9: Summary of SLOs. This table presents the number of days the Bank of Canada conducted an overnight securities lending operation (TotSLONum), total par value of the bond loaned out (TotSLOVol), and the total number of bidders for the bond (TotSLOBids) during the period from August 28, 2009, to December 31, 2015. The statistics are tabulated separately for three levels of the overnight target rate indicated and for $2 \mathrm{Y}, 5 \mathrm{Y}$ and $10 \mathrm{Y}$ Government of Canada debt securities. 


\begin{tabular}{|c|c|c|c|c|c|c|}
\hline & All & Bch & Non-bch & $2 \mathrm{Y}$ & $5 \mathrm{Y}$ & $10 \mathrm{Y}$ \\
\hline BorrowVol PreSLO $\left._{t} \times 10^{10}\right)$ & $\begin{array}{l}-1.29 \\
(-2.11)\end{array}$ & $\begin{array}{c}-1.65 \\
(-2.00)\end{array}$ & $\begin{array}{l}-3.99 \\
(-2.81)\end{array}$ & $\begin{array}{l}-1.14 \\
(-0.95)\end{array}$ & $\begin{array}{l}-2.43 \\
(-2.34)\end{array}$ & $\begin{array}{l}-4.64 \\
(-2.49)\end{array}$ \\
\hline BorrowFee $e_{t}^{\text {PreSLO }}$ & $\begin{array}{c}3.14 \\
(23.83)\end{array}$ & $\begin{array}{c}3.12 \\
(12.04)\end{array}$ & $\begin{array}{c}2.99 \\
(18.23)\end{array}$ & $\begin{array}{c}4.26 \\
(8.66)\end{array}$ & $\begin{array}{c}3.15 \\
(14.69)\end{array}$ & $\begin{array}{c}2.80 \\
(13.46)\end{array}$ \\
\hline TotSLOVol $l_{t-1}\left(\times 10^{9}\right)$ & $\begin{array}{c}3.96 \\
(14.64)\end{array}$ & $\begin{array}{c}2.12 \\
(5.88)\end{array}$ & $\begin{array}{c}6.35 \\
(14.40)\end{array}$ & $\begin{array}{c}1.48 \\
(1.94)\end{array}$ & $\begin{array}{c}3.65 \\
(8.70)\end{array}$ & $\begin{array}{c}4.60 \\
(10.36)\end{array}$ \\
\hline TotSLONum t-1 $_{1}$ & $\begin{array}{c}0.01 \\
(9.30)\end{array}$ & $\begin{array}{c}0.01 \\
(4.18)\end{array}$ & $\begin{array}{c}0.01 \\
(6.70)\end{array}$ & $\begin{array}{l}-0.01 \\
(-0.24)\end{array}$ & $\begin{array}{c}0.01 \\
(4.12)\end{array}$ & $\begin{array}{c}0.01 \\
(6.79)\end{array}$ \\
\hline NetOutstand $d_{t-1}\left(\times 10^{10}\right)$ & $\begin{array}{l}-0.99 \\
(-6.18)\end{array}$ & $\begin{array}{l}-0.85 \\
(-2.60)\end{array}$ & $\begin{array}{l}-1.00 \\
(-5.07)\end{array}$ & $\begin{array}{c}0.36 \\
(0.78)\end{array}$ & $\begin{array}{l}-1.45 \\
(-3.40)\end{array}$ & $\begin{array}{l}-1.74 \\
(-4.56)\end{array}$ \\
\hline FornInstHold $d_{t-1}\left(\times 10^{10}\right)$ & $\begin{array}{c}2.82 \\
(6.08)\end{array}$ & $\begin{array}{c}3.12 \\
(3.24)\end{array}$ & $\begin{array}{c}2.93 \\
(5.24)\end{array}$ & $\begin{array}{l}-2.88 \\
(-1.63)\end{array}$ & $\begin{array}{c}2.71 \\
(3.63)\end{array}$ & $\begin{array}{c}5.12 \\
(4.57)\end{array}$ \\
\hline SecLendUtil $t_{t-1}$ & $\begin{array}{c}1.03 \\
(5.38)\end{array}$ & $\begin{array}{c}0.27 \\
(0.88)\end{array}$ & $\begin{array}{c}1.64 \\
(5.95)\end{array}$ & $\begin{array}{c}1.44 \\
(2.97)\end{array}$ & $\begin{array}{c}0.08 \\
(0.27)\end{array}$ & $\begin{array}{c}1.34 \\
(3.58)\end{array}$ \\
\hline PDInvPostPrevAucTm $m_{t}\left(\times 10^{10}\right)$ & $\begin{array}{l}-0.62 \\
(-2.31)\end{array}$ & $\begin{array}{c}0.85 \\
(1.50)\end{array}$ & $\begin{array}{l}-1.21 \\
(-3.54)\end{array}$ & $\begin{array}{l}-1.22 \\
(-0.97)\end{array}$ & $\begin{array}{l}-0.69 \\
(-1.65)\end{array}$ & $\begin{array}{l}-0.95 \\
(-1.93)\end{array}$ \\
\hline DaysPrevAucTm ${ }_{t}$ & $\begin{array}{c}0.00 \\
(1.29)\end{array}$ & $\begin{array}{c}0.00 \\
(0.13)\end{array}$ & $\begin{array}{c}0.00 \\
(1.24)\end{array}$ & $\begin{array}{c}0.01 \\
(1.28)\end{array}$ & $\begin{array}{c}0.00 \\
(0.75)\end{array}$ & $\begin{array}{c}0.00 \\
(0.59)\end{array}$ \\
\hline $\operatorname{SizeNextAucTm}_{t}\left(\times 10^{10}\right)$ & $\begin{array}{l}-3.84 \\
(-2.96)\end{array}$ & $\begin{array}{l}-5.81 \\
(-2.26)\end{array}$ & $\begin{array}{l}-3.27 \\
(-1.91)\end{array}$ & $\begin{array}{l}-4.61 \\
(-0.80)\end{array}$ & $\begin{array}{l}-7.51 \\
(-1.81)\end{array}$ & $\begin{array}{c}-6.62 \\
(-1.34)\end{array}$ \\
\hline DaysNextAucTm $_{t}$ & $\begin{array}{c}0.00 \\
(-1.40)\end{array}$ & $\begin{array}{c}0.00 \\
(-1.24)\end{array}$ & $\begin{array}{c}0.00 \\
(-0.94)\end{array}$ & $\begin{array}{c}0.01 \\
(0.96)\end{array}$ & $\begin{array}{c}0.00 \\
(0.65)\end{array}$ & $\begin{array}{c}0.00 \\
(-2.09)\end{array}$ \\
\hline IndDelivFut $t_{t-1}$ & $\begin{array}{c}0.43 \\
(5.93)\end{array}$ & $\begin{array}{c}0.26 \\
(1.23)\end{array}$ & $\begin{array}{c}0.36 \\
(4.14)\end{array}$ & $\begin{array}{c}0.73 \\
(2.08)\end{array}$ & $\begin{array}{c}0.33 \\
(3.04)\end{array}$ & $\begin{array}{c}0.53 \\
(3.71)\end{array}$ \\
\hline IndDelivMthFut $t_{t-1}$ & $\begin{array}{l}-0.16 \\
(-1.79)\end{array}$ & $\begin{array}{l}-0.06 \\
(-0.47)\end{array}$ & $\begin{array}{l}-0.15 \\
(-1.27)\end{array}$ & $\begin{array}{l}-0.38 \\
(-1.21)\end{array}$ & $\begin{array}{c}-0.18 \\
(-1.39)\end{array}$ & $\begin{array}{c}-0.13 \\
(-0.87)\end{array}$ \\
\hline $3 m O n t G o C Y l d S p r_{t-1}$ & $\begin{array}{c}1.63 \\
(2.84)\end{array}$ & $\begin{array}{c}2.40 \\
(2.22)\end{array}$ & $\begin{array}{c}1.59 \\
(2.18)\end{array}$ & $\begin{array}{c}2.51 \\
(1.25)\end{array}$ & $\begin{array}{c}2.78 \\
(3.04)\end{array}$ & $\begin{array}{c}1.30 \\
(1.34)\end{array}$ \\
\hline $10 y O n t G o C Y l d S p r_{t-1}$ & $\begin{array}{l}-1.10 \\
(-4.25)\end{array}$ & $\begin{array}{c}-1.23 \\
(-2.34)\end{array}$ & $\begin{array}{l}-0.69 \\
(-2.16)\end{array}$ & $\begin{array}{l}-0.27 \\
(-0.27)\end{array}$ & $\begin{array}{l}-1.64 \\
(-3.67)\end{array}$ & $\begin{array}{l}-0.26 \\
(-0.54)\end{array}$ \\
\hline $3 m C p G o C Y l d S p r_{t-1}$ & $\begin{array}{c}0.52 \\
(1.27)\end{array}$ & $\begin{array}{c}1.14 \\
(1.42)\end{array}$ & $\begin{array}{c}0.41 \\
(0.82)\end{array}$ & $\begin{array}{c}0.65 \\
(0.38)\end{array}$ & $\begin{array}{c}0.66 \\
(1.01)\end{array}$ & $\begin{array}{c}0.82 \\
(1.19)\end{array}$ \\
\hline $\mathrm{Age}_{t}$ & $\begin{array}{c}-0.07 \\
(-3.53) \\
\end{array}$ & $\begin{array}{c}-0.23 \\
(-2.49) \\
\end{array}$ & $\begin{array}{l}-0.06 \\
(-2.60)\end{array}$ & $\begin{array}{c}0.18 \\
(0.99)\end{array}$ & $\begin{array}{l}-0.23 \\
(-4.93)\end{array}$ & $\begin{array}{l}-0.08 \\
(-2.27)\end{array}$ \\
\hline $\mathrm{N}$ & 33011 & 6063 & 26948 & 10214 & 11699 & 11098 \\
\hline Pseudo- $R^{2}(\%)$ & 43.86 & 39.22 & 47.43 & 57.05 & 42.96 & 41.97 \\
\hline
\end{tabular}

Table 10: Expectation of SLO announcement. This table presents the coefficients of the probit model for the expectation of SLO in individual securities, with the Z-statistic reported in parentheses below the coefficient. Each column presents the results for the sample indicated in the first row. 'Bch', 'Non-bch', ' $2 \mathrm{Y}$ ', ' $5 \mathrm{Y}$ ' and ' $10 \mathrm{Y}$ ' represent benchmark bonds, non-benchmark bonds, and bonds with 2, 5, and 10 years to maturity at issue, respectively. Our data span the period from August 28, 2009, to December 31, 2015. 


\begin{tabular}{|c|c|c|c|c|c|c|}
\hline & All & Bch & Non-bch & $2 \mathrm{Y}$ & $5 \mathrm{Y}$ & $10 \mathrm{Y}$ \\
\hline BorrowVol $l_{t}^{\text {PreSLO }}$ & $\begin{array}{c}0.00 \\
(0.25)\end{array}$ & $\begin{array}{c}-0.04 \\
(-2.41)\end{array}$ & $\begin{array}{l}-0.04 \\
(-3.33)\end{array}$ & $\begin{array}{c}0.00 \\
(0.23)\end{array}$ & $\begin{array}{l}-0.01 \\
(-1.61)\end{array}$ & $\begin{array}{c}-0.04 \\
(-4.36)\end{array}$ \\
\hline BorrowFee $_{t}^{\text {PreSLO }}\left(\times 10^{-8}\right)$ & $\begin{array}{c}1.69 \\
(32.62)\end{array}$ & $\begin{array}{c}5.84 \\
(12.38)\end{array}$ & $\begin{array}{c}3.26 \\
(21.52)\end{array}$ & $\begin{array}{c}8.09 \\
(9.52)\end{array}$ & $\begin{array}{c}3.04 \\
(16.16)\end{array}$ & $\begin{array}{c}1.83 \\
(16.50)\end{array}$ \\
\hline TotSLOVol $_{t-1}$ & $\begin{array}{c}0.47 \\
(46.61)\end{array}$ & $\begin{array}{c}0.57 \\
(9.01)\end{array}$ & $\begin{array}{c}0.80 \\
(24.27)\end{array}$ & $\begin{array}{c}0.39 \\
(2.87)\end{array}$ & $\begin{array}{c}0.61 \\
(18.79)\end{array}$ & $\begin{array}{c}0.56 \\
(24.86)\end{array}$ \\
\hline $\operatorname{TotSLONum}_{t-1}\left(\times 10^{-6}\right)$ & $\begin{array}{c}0.67 \\
(17.01)\end{array}$ & $\begin{array}{c}2.34 \\
(3.87)\end{array}$ & $\begin{array}{c}0.83 \\
(7.81)\end{array}$ & $\begin{array}{c}3.98 \\
(1.05)\end{array}$ & $\begin{array}{c}1.64 \\
(5.21)\end{array}$ & $\begin{array}{c}0.66 \\
(10.27)\end{array}$ \\
\hline NetOutstand $d_{t-1}(\times 100)$ & $\begin{array}{l}-0.31 \\
(-6.36)\end{array}$ & $\begin{array}{l}-1.33 \\
(-2.46)\end{array}$ & $\begin{array}{l}-0.75 \\
(-4.93)\end{array}$ & $\begin{array}{c}0.94 \\
(1.11)\end{array}$ & $\begin{array}{l}-1.10 \\
(-3.25)\end{array}$ & $\begin{array}{c}-0.61 \\
(-3.81)\end{array}$ \\
\hline FornInstHold $_{t-1}(\times 100)$ & $\begin{array}{c}1.83 \\
(11.20)\end{array}$ & $\begin{array}{c}8.29 \\
(4.87)\end{array}$ & & $\begin{array}{l}-3.39 \\
(-1.10)\end{array}$ & $\begin{array}{l}3.64 \\
(5.6)\end{array}$ & $\begin{array}{c}3.01 \\
(5.57)\end{array}$ \\
\hline SecLendUtil $l_{t-1}\left(\times 10^{-8}\right)$ & $\begin{array}{l}-0.03 \\
(-0.56)\end{array}$ & $\begin{array}{c}-0.34 \\
(-0.67)\end{array}$ & $\begin{array}{c}0.38 \\
(2.09)\end{array}$ & $\begin{array}{c}1.20 \\
(1.53)\end{array}$ & $\begin{array}{l}-0.18 \\
(-0.71)\end{array}$ & $\begin{array}{c}0.01 \\
(0.05)\end{array}$ \\
\hline PDInvPostPrevAucTm ${ }_{t}(\times 100)$ & $\begin{array}{l}-0.36 \\
(-3.63)\end{array}$ & $\begin{array}{c}1.90 \\
(1.85)\end{array}$ & $\begin{array}{l}-1 \\
(-4\end{array}$ & $\begin{array}{l}-1.52 \\
(-0.72)\end{array}$ & $\begin{array}{l}-0.36 \\
(-1.00)\end{array}$ & $\begin{array}{l}-1.09 \\
(-4.15)\end{array}$ \\
\hline DaysPrevAucTm $m_{t}\left(\times 10^{-5}\right)$ & $\begin{array}{l}-0.20 \\
(-0.48)\end{array}$ & $\begin{array}{c}0.67 \\
(0.17)\end{array}$ & $\begin{array}{l}1.2 \\
(1 .\end{array}$ & $\begin{array}{c}5.04 \\
(0.39)\end{array}$ & $\begin{array}{l}-2.18 \\
(-1.23)\end{array}$ & $\begin{array}{l}-0.41 \\
(-0.52)\end{array}$ \\
\hline Siz & $\begin{array}{l}-0.02 \\
(-4.32)\end{array}$ & $\begin{array}{l}-0.09 \\
(-2.00)\end{array}$ & $\begin{array}{l}-0 \\
(-2\end{array}$ & $\begin{array}{l}-0.18 \\
(-1.78)\end{array}$ & $\begin{array}{c}-0.02 \\
(-0.69)\end{array}$ & $\begin{array}{c}-0.02 \\
(-1.00)\end{array}$ \\
\hline DaysNextAucTm $_{t}\left(\times 10^{-5}\right)$ & $\begin{array}{l}-1.63 \\
(-3.99)\end{array}$ & $\begin{array}{c}-6.86 \\
(-1.73)\end{array}$ & $\begin{array}{l}-0.83 \\
(-0.71)\end{array}$ & $\begin{array}{c}1.46 \\
(0.14)\end{array}$ & $\begin{array}{l}-2.32 \\
(-1.27)\end{array}$ & $\begin{array}{l}-3.11 \\
(-3.84)\end{array}$ \\
\hline IndDelivFut $_{t-1}\left(\times 10^{-7}\right)$ & $\begin{array}{c}1.83 \\
(7.12)\end{array}$ & $\begin{array}{c}2.93 \\
(0.80)\end{array}$ & $\begin{array}{c}3.68 \\
(4.98)\end{array}$ & $\begin{array}{c}7.94 \\
(1.49)\end{array}$ & $\begin{array}{c}2.49 \\
(2.65)\end{array}$ & $\begin{array}{l}2.77 \\
(3.9)\end{array}$ \\
\hline IndDelivMthFut $_{t-1}\left(\times 10^{-7}\right)$ & $\begin{array}{l}-0.51 \\
(-1.65)\end{array}$ & $\begin{array}{c}-0.37 \\
(-0.15)\end{array}$ & $\begin{array}{l}-2.06 \\
(-2.02)\end{array}$ & $\begin{array}{c}-5.18 \\
(-0.93)\end{array}$ & $\begin{array}{l}-1.28 \\
(-1.16)\end{array}$ & $\begin{array}{c}-0.54 \\
(-0.75)\end{array}$ \\
\hline $3 m O n t G o C Y l d S p r_{t-1}\left(\times 10^{-8}\right)$ & $\begin{array}{l}-0.08 \\
(-0.40)\end{array}$ & $\begin{array}{c}1.41 \\
(0.70)\end{array}$ & $\begin{array}{l}1.98 \\
(3.09)\end{array}$ & $\begin{array}{c}2.25 \\
(0.60)\end{array}$ & $\begin{array}{l}1.86 \\
(2.38)\end{array}$ & $\begin{array}{l}-0.23 \\
(-0.47)\end{array}$ \\
\hline $10 y O n t G o C Y l d S p r_{t-1}\left(\times 10^{-8}\right)$ & $\begin{array}{l}-0.26 \\
(-2.82)\end{array}$ & $\begin{array}{l}-1.09 \\
(-1.17)\end{array}$ & $\begin{array}{l}-0.90 \\
(-3.28)\end{array}$ & $\begin{array}{l}-1.24 \\
(-0.73)\end{array}$ & $\begin{array}{l}-0.65 \\
(-1.74)\end{array}$ & $\begin{array}{l}-0.26 \\
(-1.21)\end{array}$ \\
\hline $3 m C p G o C Y l d S p r_{t-1}\left(\times 10^{-8}\right)$ & $\begin{array}{l}-0.22 \\
(-1.48)\end{array}$ & $\begin{array}{l}-0.20 \\
(-0.13)\end{array}$ & $\begin{array}{c}0.03 \\
(0.07)\end{array}$ & $\begin{array}{l}-2.55 \\
(-0.91)\end{array}$ & $\begin{array}{c}0.12 \\
(0.20)\end{array}$ & $\begin{array}{c}0.01 \\
(0.04)\end{array}$ \\
\hline $\operatorname{Age}_{t}\left(\times 10^{-7}\right)$ & $\begin{array}{c}-0.73 \\
(-9.07) \\
\end{array}$ & $\begin{array}{c}-4.87 \\
(-2.97) \\
\end{array}$ & $\begin{array}{l}-1.38 \\
(-6.28) \\
\end{array}$ & $\begin{array}{l}-2.06 \\
(-0.63) \\
\end{array}$ & $\begin{array}{l}-2.79 \\
(-6.84) \\
\end{array}$ & $\begin{array}{l}-0.79 \\
(-4.47) \\
\end{array}$ \\
\hline 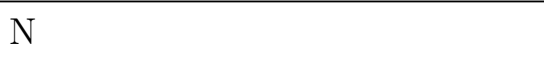 & 3301 & 6063 & 26948 & 10214 & 11699 & 11098 \\
\hline Pseudo- $R^{2}(\%)$ & -0.30 & 0.06 & 0.07 & 0.27 & 0.08 & -0.08 \\
\hline
\end{tabular}

Table 11: Expectation of SLO volume. This table presents the coefficients of the Tobit model - with lower and upper bounds at 0 and 1.5 billion, respectively - for the volume of lending in an SLO for each security, with the T-statistic reported in parentheses below the coefficient. Each column presents the results for the sample indicated in the first row. 'Bch', 'Non-bch', ' $2 \mathrm{Y}$ ', ' $5 \mathrm{Y}$ ' and ' $10 \mathrm{Y}$ ' represent benchmark bonds, non-benchmark bonds, and bonds with 2, 5, and 10 years to maturity at issue, respectively. The data span the period from August 28, 2009, to December 31, 2015. 


\begin{tabular}{|c|c|c|c|c|c|c|}
\hline & All & Bch & Non-bch & $2 \mathrm{Y}$ & $5 \mathrm{Y}$ & $10 \mathrm{Y}$ \\
\hline \multicolumn{7}{|c|}{ Panel A: 24-hour change in bond borrowing fee } \\
\hline SLO_Comm $m_{t}$ & $\begin{array}{c}0.06 \\
(11.88)\end{array}$ & $\begin{array}{c}0.05 \\
(5.40)\end{array}$ & $\begin{array}{c}0.07 \\
(10.34)\end{array}$ & $\begin{array}{c}0.05 \\
(2.66)\end{array}$ & $\begin{array}{c}0.06 \\
(7.89)\end{array}$ & $\begin{array}{c}0.07 \\
(7.96)\end{array}$ \\
\hline $\operatorname{SLOVol} t\left(\times 10^{10}\right)$ & $\begin{array}{l}-2.00 \\
(-4.80)\end{array}$ & $\begin{array}{l}-1.67 \\
(-2.90)\end{array}$ & $\begin{array}{l}-2.06 \\
(-3.47)\end{array}$ & $\begin{array}{l}-1.29 \\
(-1.36)\end{array}$ & $\begin{array}{l}-1.62 \\
(-3.12)\end{array}$ & $\begin{array}{l}-2.32 \\
(-3.05)\end{array}$ \\
\hline$\Delta$ NetOutstand $d_{t+1}\left(\times 10^{12}\right)$ & $\begin{array}{l}-0.03 \\
(-0.05)\end{array}$ & $\begin{array}{c}0.09 \\
(0.13)\end{array}$ & $\begin{array}{c}-0.64 \\
(-0.51)\end{array}$ & $\begin{array}{c}0.10 \\
(0.14)\end{array}$ & $\begin{array}{c}2.82 \\
(0.81)\end{array}$ & $\begin{array}{l}-2.09 \\
(-1.26)\end{array}$ \\
\hline$\Delta$ FornInstHold $t_{t+1}\left(\times 10^{11}\right)$ & $\begin{array}{c}3.90 \\
(3.55)\end{array}$ & $\begin{array}{c}5.23 \\
(2.70)\end{array}$ & $\begin{array}{l}3.30 \\
(2.46)\end{array}$ & $\begin{array}{c}2.37 \\
(2.36)\end{array}$ & $\begin{array}{c}7.94 \\
(3.53)\end{array}$ & $\begin{array}{c}0.48 \\
(0.23)\end{array}$ \\
\hline$\Delta F u t O I_{t+1}\left(\times 10^{-11}\right)$ & $\begin{array}{l}-0.08 \\
(-1.54)\end{array}$ & $\begin{array}{c}0.05 \\
(0.59)\end{array}$ & $\begin{array}{l}-0.16 \\
(-2.58)\end{array}$ & $\begin{array}{l}-2.50 \\
(-1.46)\end{array}$ & $\begin{array}{c}0.92 \\
(0.39)\end{array}$ & $\begin{array}{l}-0.07 \\
(-1.48)\end{array}$ \\
\hline$\Delta$ FutOIDelivMth $h_{t+1}\left(\times 10^{12}\right)$ & $\begin{array}{l}-3.14 \\
(-0.88)\end{array}$ & $\begin{array}{c}3.96 \\
(1.14)\end{array}$ & $\begin{array}{l}-7.84 \\
(-1.43)\end{array}$ & $\begin{array}{l}7.78 \\
(0.82)\end{array}$ & $\begin{array}{l}-19.80 \\
(-1.03)\end{array}$ & $\begin{array}{c}-2.54 \\
(-0.65)\end{array}$ \\
\hline$\Delta O N g t_{t+1}$ & $\begin{array}{l}-0.10 \\
(-2.81)\end{array}$ & $\begin{array}{l}-0.09 \\
(-1.12)\end{array}$ & $\begin{array}{l}-0.10 \\
(-2.55)\end{array}$ & $\begin{array}{l}-0.10 \\
(-1.66)\end{array}$ & $\begin{array}{l}-0.10 \\
(-2.10)\end{array}$ & $\begin{array}{c}-0.12 \\
(-1.62)\end{array}$ \\
\hline$\Delta 3 m O n t G o C Y l d S p r_{t+1}$ & $\begin{array}{c}0.01 \\
(0.42)\end{array}$ & $\begin{array}{c}0.04 \\
(0.74)\end{array}$ & $\begin{array}{l}0.01 \\
(0.17)\end{array}$ & $\begin{array}{l}-0.06 \\
(-0.85)\end{array}$ & $\begin{array}{l}-0 \\
(-0\end{array}$ & $\begin{array}{c}0.11 \\
(2.24)\end{array}$ \\
\hline$\Delta 10 y O n t G o C Y l d S p r_{t+1}$ & $\begin{array}{l}-0.03 \\
(-1.42)\end{array}$ & $\begin{array}{l}-0.03 \\
(-0.52)\end{array}$ & $\begin{array}{c}-0.03 \\
(-1.31)\end{array}$ & $\begin{array}{c}0.01 \\
(0.22)\end{array}$ & $\begin{array}{c}-0.03 \\
(-0.90)\end{array}$ & $\begin{array}{c}-0.07 \\
(-1.46)\end{array}$ \\
\hline$\Delta 3 m C p G o C Y l d S p r_{t+1}$ & $\begin{array}{c}0.01 \\
(1.05)\end{array}$ & $\begin{array}{c}0.01 \\
(0.22)\end{array}$ & $\begin{array}{c}0.01 \\
(1.09)\end{array}$ & $\begin{array}{c}0.03 \\
(2.42)\end{array}$ & $\begin{array}{c}0.00 \\
(-0.08)\end{array}$ & $\begin{array}{c}0.00 \\
(0.11)\end{array}$ \\
\hline$\Delta I n d B c h_{t+1}$ & $\begin{array}{l}-0.01 \\
(-0.79) \\
\end{array}$ & $\begin{array}{c}-0.01 \\
(-0.87) \\
\end{array}$ & & $\begin{array}{c}-0.02 \\
(-0.85) \\
\end{array}$ & $\begin{array}{l}-0.01 \\
(-0.70) \\
\end{array}$ & $\begin{array}{c}0.02 \\
(1.05) \\
\end{array}$ \\
\hline $\mathrm{N}$ & 31404 & 5989 & & 9862 & 11111 & 11098 \\
\hline & 2.37 & 2.57 & 2.29 & 0.61 & 2.63 & 1.04 \\
\hline \multicolumn{7}{|c|}{ Panel B: 24-hour change in bond borrowing volume } \\
\hline$S L O \_C c$ & $\begin{array}{c}0.35 \\
(1.67)\end{array}$ & $\begin{array}{c}0.56 \\
(0.78)\end{array}$ & $\begin{array}{c}0.21 \\
(2.21)\end{array}$ & $\begin{array}{c}1.41 \\
(0.62)\end{array}$ & $\begin{aligned} 0 . & \\
(1 . & \end{aligned}$ & $\begin{array}{c}0.17 \\
(1.49)\end{array}$ \\
\hline SLOVol $l_{t}$ & $\begin{array}{l}-0.06 \\
(-0.48)\end{array}$ & $\begin{array}{l}-0.18 \\
(-0.72)\end{array}$ & $\begin{array}{c}0.07 \\
(0.56)\end{array}$ & $\begin{array}{c}-0.77 \\
(-1.35)\end{array}$ & $\begin{array}{c}0.06 \\
(0.40)\end{array}$ & $\begin{array}{c}0.11 \\
(0.86)\end{array}$ \\
\hline$\Delta$ NetOutstand $d_{t+1}$ & $\begin{array}{c}0.13 \\
(4.81)\end{array}$ & $\begin{array}{c}0.15 \\
(3.60)\end{array}$ & $\begin{array}{c}0.11 \\
(3.22)\end{array}$ & $\begin{array}{c}0.11 \\
(3.82)\end{array}$ & $\begin{array}{c}0.14 \\
(1.12)\end{array}$ & $\begin{array}{c}0.24 \\
(3.33)\end{array}$ \\
\hline$\Delta$ FornInstHold $_{t+1}$ & $\begin{array}{l}-0 . \\
(-1\end{array}$ & $\begin{aligned} 0 . \\
(0\end{aligned}$ & $\begin{array}{l}-0 \\
(-2\end{array}$ & $\begin{array}{l}-0.07 \\
(-0.45)\end{array}$ & $\begin{array}{c}0.01 \\
(0.11)\end{array}$ & $\begin{array}{c}-0.18 \\
(-1.90)\end{array}$ \\
\hline$\Delta F u t O I_{t+1}$ & $\begin{array}{c}0.00 \\
(0.39)\end{array}$ & $\begin{array}{c}0.00 \\
(-0.28)\end{array}$ & $\begin{array}{c}0.00 \\
(1.00)\end{array}$ & $\begin{array}{l}-0.07 \\
(-0.21)\end{array}$ & $\begin{array}{c}0.08 \\
(0.57)\end{array}$ & $\begin{array}{c}0.00 \\
(0.36)\end{array}$ \\
\hline$\Delta F u t O I D e l i v M t h_{t+1}$ & $\begin{array}{c}0.22 \\
(4.00)\end{array}$ & $\begin{array}{c}0.16 \\
(2.17)\end{array}$ & $\begin{array}{c}0.26 \\
(3.41)\end{array}$ & $\begin{array}{c}0.26 \\
(1.27)\end{array}$ & $\begin{array}{c}0.31 \\
(1.79)\end{array}$ & $\begin{array}{c}0.22 \\
(3.63)\end{array}$ \\
\hline$\Delta O N \operatorname{tgt}_{t+1}\left(\times 10^{-8}\right)$ & $\begin{array}{c}5.89 \\
(2.37)\end{array}$ & $\begin{array}{c}8.21 \\
(1.09)\end{array}$ & $\begin{array}{l}5.28 \\
(2.20)\end{array}$ & $\begin{array}{c}8.14 \\
(1.35)\end{array}$ & $\begin{array}{c}7.11 \\
(1.93)\end{array}$ & $\begin{array}{c}3.26 \\
(0.95)\end{array}$ \\
\hline$\Delta 3 m O n t G o C Y l d S p r_{t+1}\left(\times 10^{-8}\right)$ & $\begin{array}{l}-0.71 \\
(-0.40)\end{array}$ & $\begin{array}{l}1.28 \\
(0.23)\end{array}$ & $\begin{array}{l}-1.34 \\
(-0.79)\end{array}$ & $\begin{array}{l}-4.19 \\
(-1.02)\end{array}$ & $\begin{array}{l}-1.58 \\
(-0.59)\end{array}$ & $\begin{array}{c}3.46 \\
(1.62)\end{array}$ \\
\hline$\Delta 10 y$ OntGoCYldSpr $r_{t+1}\left(\times 10^{-8}\right)$ & $\begin{array}{l}-3.11 \\
(-1.78)\end{array}$ & $\begin{array}{l}-8.15 \\
(-1.36)\end{array}$ & $\begin{array}{l}-1.86 \\
(-1.14)\end{array}$ & $\begin{array}{l}-0.95 \\
(-0.23)\end{array}$ & $\begin{array}{l}-4.89 \\
(-1.95)\end{array}$ & $\begin{array}{l}-3.33 \\
(-1.49)\end{array}$ \\
\hline$\Delta 3 m C p G o C Y l d S p r_{t+1}\left(\times 10^{-8}\right)$ & $\begin{array}{c}0.66 \\
(0.96)\end{array}$ & $\begin{array}{c}3.77 \\
(1.82)\end{array}$ & $\begin{array}{c}0.03 \\
(0.04)\end{array}$ & $\begin{array}{c}0.77 \\
(0.42)\end{array}$ & $\begin{array}{c}1.83 \\
(2.03)\end{array}$ & $\begin{array}{c}-0.27 \\
(-0.39)\end{array}$ \\
\hline$\Delta \operatorname{IndBch} h_{t+1}\left(\times 10^{-8}\right)$ & $\begin{array}{l}-2.59 \\
(-2.44) \\
\end{array}$ & $\begin{array}{l}-2.69 \\
(-2.50) \\
\end{array}$ & & $\begin{array}{l}-3.65 \\
(-2.40) \\
\end{array}$ & $\begin{array}{l}-1.72 \\
(-0.79) \\
\end{array}$ & $\begin{array}{l}-0.20 \\
(-0.20)\end{array}$ \\
\hline$N$ & 33011 & 6063 & 26948 & 10214 & 11699 & 11098 \\
\hline $\operatorname{Adj} R^{2}(\%)$ & 0.39 & 0.50 & 0.38 & 0.37 & 0.26 & 1.04 \\
\hline
\end{tabular}

Table 12: Communication effect SLO announcement. This table presents the estimates of the coefficients of the regression $\Delta w=\delta+\lambda S L O \_C o m m+\gamma^{\prime} U+\eta$ along with the heteroskedasticity-consistent T-statistics in parentheses. In Panel A (B), $\Delta w$ is the 24-hour change in the securities borrowing fee (securities borrowing volume) after the scheduled time of the OMO. SLO_Comm is the estimated surprise due to the communication of the SLO, and $U$ is the vector of control variables. Each column presents the results for the sample indicated in the first row. 'Bch', 'Non-bch', ' $2 \mathrm{Y}$ ', ' $5 \mathrm{Y}$ ' and ' $10 \mathrm{Y}$ ' represent benchmark bonds, non-benchmark bonds, and bonds with 2, 5, and 10 years to maturity at issue, respectively. The sample spans the period from August 28, 2009, to December 31, 2015. 


\begin{tabular}{|c|c|c|c|c|c|c|}
\hline & All & Bch & Non-bch & $2 \mathrm{Y}$ & $5 \mathrm{Y}$ & $10 \mathrm{Y}$ \\
\hline \multicolumn{7}{|c|}{ Panel A: 24-hour change in bond borrowing fee } \\
\hline SLOVol_Comm_Effect $\left(\times 10^{10}\right)$ & $\begin{array}{c}5.36 \\
(6.79)\end{array}$ & $\begin{array}{c}4.57 \\
(4.25)\end{array}$ & $\begin{array}{c}5.98 \\
(5.58)\end{array}$ & $\begin{array}{c}6.39 \\
(3.95)\end{array}$ & $\begin{array}{c}4.83 \\
(4.89)\end{array}$ & $\begin{array}{c}4.76 \\
(3.16)\end{array}$ \\
\hline SLOVol $t\left(\times 10^{10}\right)$ & $\begin{array}{l}-3.79 \\
(-5.50)\end{array}$ & $\begin{array}{l}-3.84 \\
(-4.05)\end{array}$ & $\begin{array}{l}-3.02 \\
(-3.16)\end{array}$ & $\begin{array}{l}-5.29 \\
(-3.48)\end{array}$ & $\begin{array}{l}-3.15 \\
(-3.96)\end{array}$ & $\begin{array}{l}-3.04 \\
(-2.13)\end{array}$ \\
\hline$\Delta$ NetOutstand $d_{t+1}\left(\times 10^{11}\right)$ & $\begin{array}{l}-0.02 \\
(-0.34)\end{array}$ & $\begin{array}{l}-0.02 \\
(-0.27)\end{array}$ & $\begin{array}{l}-0.08 \\
(-0.68)\end{array}$ & $\begin{array}{c}0.01 \\
(0.07)\end{array}$ & $\begin{array}{c}0.24 \\
(0.72)\end{array}$ & $\begin{array}{l}-0.24 \\
(-1.41)\end{array}$ \\
\hline$\Delta$ FornInstHold ${ }_{t+1}\left(\times 10^{11}\right)$ & $\begin{array}{c}3.88 \\
(3.60)\end{array}$ & $\begin{array}{c}4.71 \\
(2.53)\end{array}$ & $\begin{array}{c}3.29 \\
(2.49)\end{array}$ & $\begin{array}{c}1.98 \\
(1.98)\end{array}$ & $\begin{array}{c}7.51 \\
(3.41)\end{array}$ & $\begin{array}{l}1.75 \\
(0.84)\end{array}$ \\
\hline$\Delta F u t O I_{t+1}\left(\times 10^{11}\right)$ & $\begin{array}{l}-0.08 \\
(-1.56)\end{array}$ & $\begin{array}{c}0.06 \\
(0.75)\end{array}$ & $\begin{array}{l}-0.17 \\
(-2.67)\end{array}$ & $\begin{array}{l}-2.41 \\
(-1.42)\end{array}$ & $\begin{array}{c}0.64 \\
(0.27)\end{array}$ & $\begin{array}{l}-0.07 \\
(-1.47)\end{array}$ \\
\hline$\Delta$ FutOIDelivMth $h_{t+1}\left(\times 10^{11}\right)$ & $\begin{array}{c}-0.36 \\
(-0.96)\end{array}$ & $\begin{array}{c}0.36 \\
(1.02)\end{array}$ & $\begin{array}{l}-0.81 \\
(-1.44)\end{array}$ & $\begin{array}{c}0.75 \\
(0.80)\end{array}$ & $\begin{array}{l}-1.72 \\
(-0.90)\end{array}$ & $\begin{array}{l}-0.31 \\
(-0.78)\end{array}$ \\
\hline$\triangle O N$ Rate $_{t+1}$ & $\begin{array}{l}-0.09 \\
(-2.24)\end{array}$ & $\begin{array}{c}-0.06 \\
(-0.66)\end{array}$ & $\begin{array}{l}-0.10 \\
(-2.19)\end{array}$ & $\begin{array}{l}-0.10 \\
(-1.66)\end{array}$ & $\begin{array}{l}-0.10 \\
(-2.04)\end{array}$ & $\begin{array}{c}-0.09 \\
(-0.90)\end{array}$ \\
\hline$\Delta 3 m O n t G o C Y l d S p r_{t+1}$ & $\begin{array}{c}0.02 \\
(0.62)\end{array}$ & $\begin{array}{c}0.05 \\
(1.04)\end{array}$ & $\begin{array}{c}0.01 \\
(0.24)\end{array}$ & $\begin{array}{l}-0.06 \\
(-0.81)\end{array}$ & $\begin{array}{l}-0.01 \\
(-0.17)\end{array}$ & $\begin{array}{c}0.12 \\
(2.53)\end{array}$ \\
\hline$\Delta 10 y O n t G o C Y l d S p r_{t+1}$ & $\begin{array}{l}-0.03 \\
(-1.47)\end{array}$ & $\begin{array}{c}-0.02 \\
(-0.42)\end{array}$ & $\begin{array}{l}-0.03 \\
(-1.34)\end{array}$ & $\begin{array}{c}0.01 \\
(0.24)\end{array}$ & $\begin{array}{l}-0.04 \\
(-1.00)\end{array}$ & $\begin{array}{l}-0.07 \\
(-1.43)\end{array}$ \\
\hline$\Delta 3 m C p G o C Y l d S p r_{t+1}$ & $\begin{array}{c}0.01 \\
(1.13)\end{array}$ & $\begin{array}{c}0.01 \\
(0.28)\end{array}$ & $\begin{array}{c}0.01 \\
(1.18)\end{array}$ & $\begin{array}{c}0.03 \\
(2.46)\end{array}$ & $\begin{array}{c}0.00 \\
(0.02)\end{array}$ & $\begin{array}{c}0.00 \\
(0.17)\end{array}$ \\
\hline$\Delta I n d B c h_{t+1}$ & $\begin{array}{l}-0.02 \\
(-0.85) \\
\end{array}$ & $\begin{array}{l}-0.02 \\
(-0.91) \\
\end{array}$ & & $\begin{array}{c}-0.02 \\
(-0.86) \\
\end{array}$ & $\begin{array}{c}-0.01 \\
(-0.63) \\
\end{array}$ & $\begin{array}{c}0.02 \\
(1.01) \\
\end{array}$ \\
\hline $\mathrm{N}$ & 3140 & 5989 & & 9862 & & 10431 \\
\hline$R^{2}(\%)$ & 0.78 & 1.48 & 0.90 & 0.71 & 1.14 & 0.65 \\
\hline \multicolumn{7}{|c|}{ Panel B: $\Delta$ BorrowVol } \\
\hline SLOVol_Cor & $\begin{array}{c}0.42 \\
(1.62)\end{array}$ & $\begin{array}{c}0.02 \\
(0.05)\end{array}$ & $\begin{array}{c}0.28 \\
(1.26)\end{array}$ & $\begin{array}{c}-0.32 \\
(-0.28)\end{array}$ & $\begin{array}{c}0.41 \\
(1.22)\end{array}$ & $\begin{array}{c}0.36 \\
(1.79)\end{array}$ \\
\hline$S L O V o l_{t}$ & $\begin{array}{l}-0.25 \\
(-1.10)\end{array}$ & $\begin{array}{c}-0.02 \\
(-0.04)\end{array}$ & $\begin{array}{l}-0.03 \\
(-0.15)\end{array}$ & $\begin{array}{l}-0.07 \\
(-0.07)\end{array}$ & $\begin{array}{l}-0.18 \\
(-0.60)\end{array}$ & $\begin{array}{l}-0.11 \\
(-0.52)\end{array}$ \\
\hline$\Delta N e t O u t s t a n d_{t+1}$ & $\begin{array}{c}0.13 \\
(4.80)\end{array}$ & $\begin{array}{c}0.15 \\
(3.60)\end{array}$ & $\begin{array}{c}0.11 \\
(3.22)\end{array}$ & $\begin{array}{c}0.11 \\
(3.81)\end{array}$ & $\begin{array}{c}0.14 \\
(1.12)\end{array}$ & $\begin{array}{c}0.24 \\
(3.33)\end{array}$ \\
\hline$\Delta$ FornInstHold $_{t+1}$ & $\begin{array}{l}-0.08 \\
(-1.12)\end{array}$ & $\begin{array}{c}0.12 \\
(0.63)\end{array}$ & $\begin{array}{l}-0.16 \\
(-2.73)\end{array}$ & $\begin{array}{l}-0.07 \\
(-0.42)\end{array}$ & $\begin{array}{c}0.00 \\
(0.02)\end{array}$ & $\begin{array}{l}-0.18 \\
(-1.91)\end{array}$ \\
\hline$\Delta F u t O I_{t+1}(\times 100)$ & $\begin{array}{c}0.15 \\
(0.38)\end{array}$ & $\begin{array}{l}-0.18 \\
(-0.25)\end{array}$ & $\begin{array}{c}0.43 \\
(0.99)\end{array}$ & $\begin{array}{l}-7.17 \\
(-0.22)\end{array}$ & $\begin{array}{c}8.12 \\
(0.57)\end{array}$ & $\begin{array}{c}0.14 \\
(0.36)\end{array}$ \\
\hline$\Delta$ FutOIDelivMth $h_{t+1}$ & $\begin{array}{c}0.22 \\
(4.00)\end{array}$ & $\begin{array}{c}0.16 \\
(2.17)\end{array}$ & $\begin{array}{c}0.26 \\
(3.41)\end{array}$ & $\begin{array}{c}0.26 \\
(1.26)\end{array}$ & $\begin{array}{c}0.31 \\
(1.79)\end{array}$ & $\begin{array}{c}0.22 \\
(3.63)\end{array}$ \\
\hline$\Delta O N$ Rate $_{t+1}\left(\times 10^{-8}\right)$ & $\begin{array}{c}5.94 \\
(2.39)\end{array}$ & $\begin{array}{c}8.44 \\
(1.12)\end{array}$ & $\begin{array}{c}5.29 \\
(2.21)\end{array}$ & $\begin{array}{c}8.14 \\
(1.35)\end{array}$ & $\begin{array}{c}7.14 \\
(1.94)\end{array}$ & $\begin{array}{c}3.36 \\
(0.98)\end{array}$ \\
\hline$\Delta 3 m O n t G o C Y l d S p r_{t+1}\left(\times 10^{-8}\right)$ & $\begin{array}{c}-0.68 \\
(-0.38)\end{array}$ & $\begin{array}{c}1.38 \\
(0.25)\end{array}$ & $\begin{array}{l}-1.33 \\
(-0.79)\end{array}$ & $\begin{array}{l}-4.13 \\
(-1.00)\end{array}$ & $\begin{array}{l}-1.58 \\
(-0.59)\end{array}$ & $\begin{array}{c}3.50 \\
(1.64)\end{array}$ \\
\hline$\Delta 10 y$ OntGoCYldSpr $r_{t+1}\left(\times 10^{-8}\right)$ & $\begin{array}{l}-3.11 \\
(-1.79)\end{array}$ & $\begin{array}{l}-8.12 \\
(-1.36)\end{array}$ & $\begin{array}{l}-1.86 \\
(-1.14)\end{array}$ & $\begin{array}{l}-0.98 \\
(-0.23)\end{array}$ & $\begin{array}{l}-4.89 \\
(-1.95)\end{array}$ & $\begin{array}{l}-3.33 \\
(-1.49)\end{array}$ \\
\hline$\Delta 3 m C p G o C Y l d S p r_{t+1}\left(\times 10^{-7}\right)$ & $\begin{array}{c}0.67 \\
(0.97)\end{array}$ & $\begin{array}{c}3.79 \\
(1.83)\end{array}$ & $\begin{array}{c}0.03 \\
(0.04)\end{array}$ & $\begin{array}{c}0.78 \\
(0.43)\end{array}$ & $\begin{array}{l}1.85 \\
(2.05)\end{array}$ & $\begin{array}{l}-0.28 \\
(-0.41)\end{array}$ \\
\hline$\Delta \operatorname{IndBch}_{t+1}\left(\times 10^{-8}\right)$ & $\begin{array}{l}-2.61 \\
(-2.45) \\
\end{array}$ & $\begin{array}{l}-2.70 \\
(-2.50) \\
\end{array}$ & & $\begin{array}{l}-3.74 \\
(-2.45) \\
\end{array}$ & $\begin{array}{l}-1.72 \\
(-0.78) \\
\end{array}$ & $\begin{array}{l}-0.20 \\
(-0.21) \\
\end{array}$ \\
\hline $\mathrm{N}$ & 33011 & 6063 & 26948 & 10214 & 11699 & 11098 \\
\hline$R^{2}(\%)$ & 0.38 & 0.47 & 0.38 & 0.33 & 0.27 & 1.04 \\
\hline
\end{tabular}

Table 13: Communication effect of SLO volume announcement. This table presents the estimates of the coefficients of the regression $\Delta w=\delta_{v}+\lambda_{v} S L O V o l_{-} C o m m+\gamma_{v}^{\prime} U+\eta_{v}$ along with the heteroskedasticityconsistent T-statistics in parentheses. In Panel A (B), $\Delta w$ is the 24-hour change in the securities borrowing fee (securities borrowing volume) after the scheduled time of the SLO. SLOVol_Comm is the surprise in SLO volume measured as the difference between the realised and expected SLO volume in each security, and $U$ is the vector of control variables. Each column presents the results for the sample indicated in the first row. 'Bch', 'Non-bch', ' $2 \mathrm{Y}$ ', '5Y' and ' $10 \mathrm{Y}$ ' represent benchmark bonds, non-benchmark bonds, and bonds with 2, 5, and 10 years to maturity at issue, respectively. The sample spans the period from August 28, 2009, to December 31, 2015. 